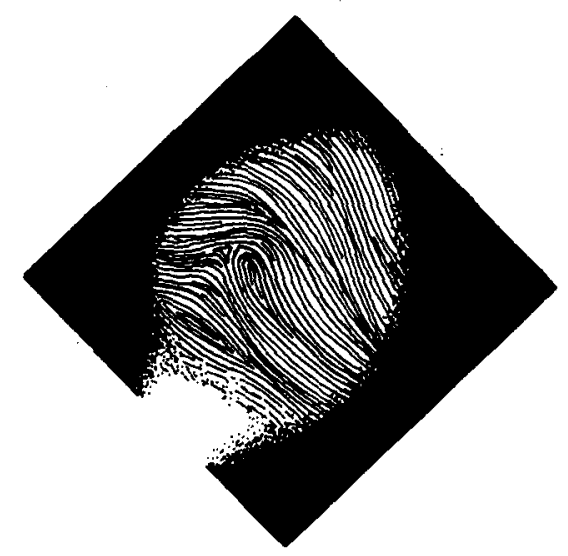

$\mathrm{DOE} / \mathrm{NE}--0066$

DE $86 \quad 011405$

\title{
Sensors and Nuclear Power Report by the Technology Transfer Sensors Task Team
}

June 1985

This document is OBRLICLYRELEASABLE ary e Brlliam Authofizing Official

Date: $04 / 27 / 2007$

\section{U.S. Department of Energy} Assistant Secretary for Nuclear Energy Washington, D.C. 20545

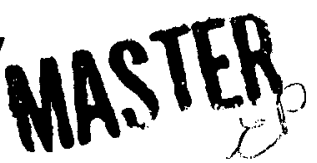




\section{DISCLAIMER}

This report was prepared as an account of work sponsored by an agency of the United States Government. Neither the United States Government nor any agency Thereof, nor any of their employees, makes any warranty, express or implied, or assumes any legal liability or responsibility for the accuracy, completeness, or usefulness of any information, apparatus, product, or process disclosed, or represents that its use would not infringe privately owned rights. Reference herein to any specific commercial product, process, or service by trade name, trademark, manufacturer, or otherwise does not necessarily constitute or imply its endorsement, recommendation, or favoring by the United States Government or any agency thereof. The views and opinions of authors expressed herein do not necessarily state or reflect those of the United States Government or any agency thereof. 


\section{DISCLAIMER}

Portions of this document may be illegible in electronic image products. Images are produced from the best available original document. 
Table of Contents

I. SUMMARY AND DEVELOPMENT NEEDS. . . . . . . . . . . . . . 1

II. TASK TEAM CHARTER AND MEMBERSHIP . . . . . . . . . . . . 7

A. Charter....................... 7

B. Membership .................. 8

III. TECHNOLOGY EVALUATION. . . . . . . . . . . . . . . . 10

A. Advanced Technology. . . . . . . . . . . . . . 10

1. Advanced Sensors and Signal Processing . . . . . . 10

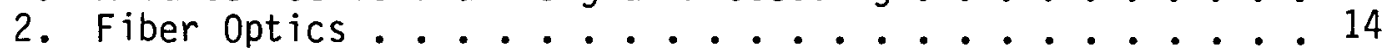

B. Plant Life Extension ................ . 18

1. Residual Life Measurement. ............. 18

2. Leak Detection ................ 21

3. In-service Inspection. . . . . . . . . . . . 24

C. Process Parameters ................ 25

1. Temperature................ 25

2. Pressure ................. 29

3. Flow.................... 31

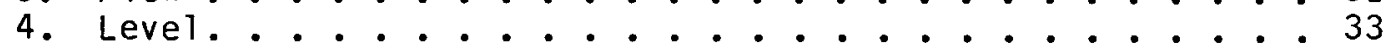

5. Radiation. . . . . . . . . . . . 36

6. Coolant Chemistry............... 38

D. Technology Transfer. . . . . . . . . . . . . 40

IV. DEVELOPMENTS UNDERWAY AND CONTACTS . . . . . . . . . . . . 43

REFERENCES ...................... 47

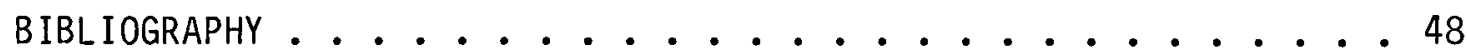

APPENDIX ............................... 67 


\section{SUMMARY AND DEVELOPMENT NEEDS}

The existing sensor systems for the basic process parameters in nuclear power plant operation have limitations with respect to accuracy, ease of maintenance and signal processing. These limitations compromise the economy of nuclear power generation. To reduce the costs and improve performance of nuclear power plant fabrication, operation, maintenance and repair we need to advance the sensor technology being applied in the nuclear industry. The economic viability and public acceptance of nuclear power will depend on how well we direct and apply technological advances to the industry.

The block diagram in Figure I-1 provides an overview of sensor development from the standpoint of what problems need to be addressed by the program. Blocks above the dotted line labeled "technology boundary" are generally considered to be beyond the scope of this program. If sensors are available or commercially attractive for development by industry there is no need to target this program in these areas. The blocks under the "technology boundary" line are the vital development areas for this program with emphasis on the topics that would enable a quantum leap forward in the technology.

This report was prepared by a team with members representing a wide range of the nuclear industry embracing the university programs, national laboratories, architect eningeers and reactor manufacturers. An intensive effort was made to survey current sensor technology, evaluate future trends and determine development needs. This included literature surveys, visits with utilities, universities, laboratories and organizations outside the nuclear industry. Several conferences were attended to take advantage of the access to experts in selected topics and to obtain opinions. Numerous telephone contacts and exchanges by mail supplemented the above efforts. Finally, the broad technical depth of the team members provided the basis for the stimulating working sessions during which this report was organized and drafted. 
I. SUMMARY AND DEVELOPMENT NEEDS (Cont inued)

For convenience of presentation, the subject of sensor development has been divided into four topic areas: advanced technology, plant life extension, process parameters, and technology transfer. Individual topics are listed in Table I-1 along with a summary of the emphasis needed on each topic denoted by an $X$ under the following column headings: apply or monitor on-going programs (the intent here is to primarily take what is already available from other programs and make it applicable to our needs); existing technology needs to be optimized; needs new development (a significant development effort is warranted on these topics to provide the sensor technology needed for future nuclear power generation). The benefits of performing the work are also categorized in Table I-1. The supporting technology evaluation for developing this list of needs is presented in the subsequent sections of this report.

To identify the sensors development needs presented in this report the overall objective has been aimed at implementing cost effective increases in nuclear power plant life and availability. The highest priority topics are related to advanced technology development and fiber optics technology is considered to be the most fruitful of these topics from the standpoint of potential cost and performance improvements. Both of these high priority topics can be effectively interfaced with ongoing projects at national facilities such as FFTF, EBR-II and HFIR. The topic of the plant life extension will become increasingly important as the current plants approach their design lifetimes. Much of the development needed in this area must be started as soon as possible if we are to take full advantage of the enormous cost benefit potential. In the area of the basic process parameters there is principally a need to monitor on-going programs and factor in any developments to the advanced sensor and signal processing developments programs.

A key element in defining development needs for sensor technology is the interface with the utilities, EPRI and the regulatory agencies. The utilities are the ultimate users of the technology and should play an active role during the planning and implementation of any sensor development programs. This approach is expected to facilitate acceptance of any 
I. SUMMARY AND DEVELOPMENT NEEDS (Cont inued)

new technology and a co-operative program is essential during the plant qualification testing. A vigorous exchange of information and joint testing programs is encouraged with both EPRI and the utilities to implement the sensor technology improvements in the nuclear industry.

The need for sensor technology is growing as a result of the increasing use of automation with the development of the highly sophisticated computer systems. Sensor technology covers a vast field because it is linked to a multitude of parameters which have to be measured, quantified or compared. The progress made in the last twenty years in computer technology allows the development of measurement and control systems with greater and greater levels of performance and sophistication. A control system can, for example, be sure of obtaining a measurement to $10-4$, but unfortunately many sensors can only provide information whose accuracy will often be of the order of one percent. Thus there exists a worrying technical gap between the abilities of sensors and those of systems of data acquisition, control and treatment. Consequently, the thrust of advanced sensors and signal processing development should be centered on an integrated approach where the sensing mechanisms will be examined with regard to existing or emerging data processing schemes and computer sophistication. The end result will be a sensor system that is: compatible with the highly sophisticated computers, reliable, rugged, fault tolerant, capable of inherent signal validation and able to make some limited decisions. 


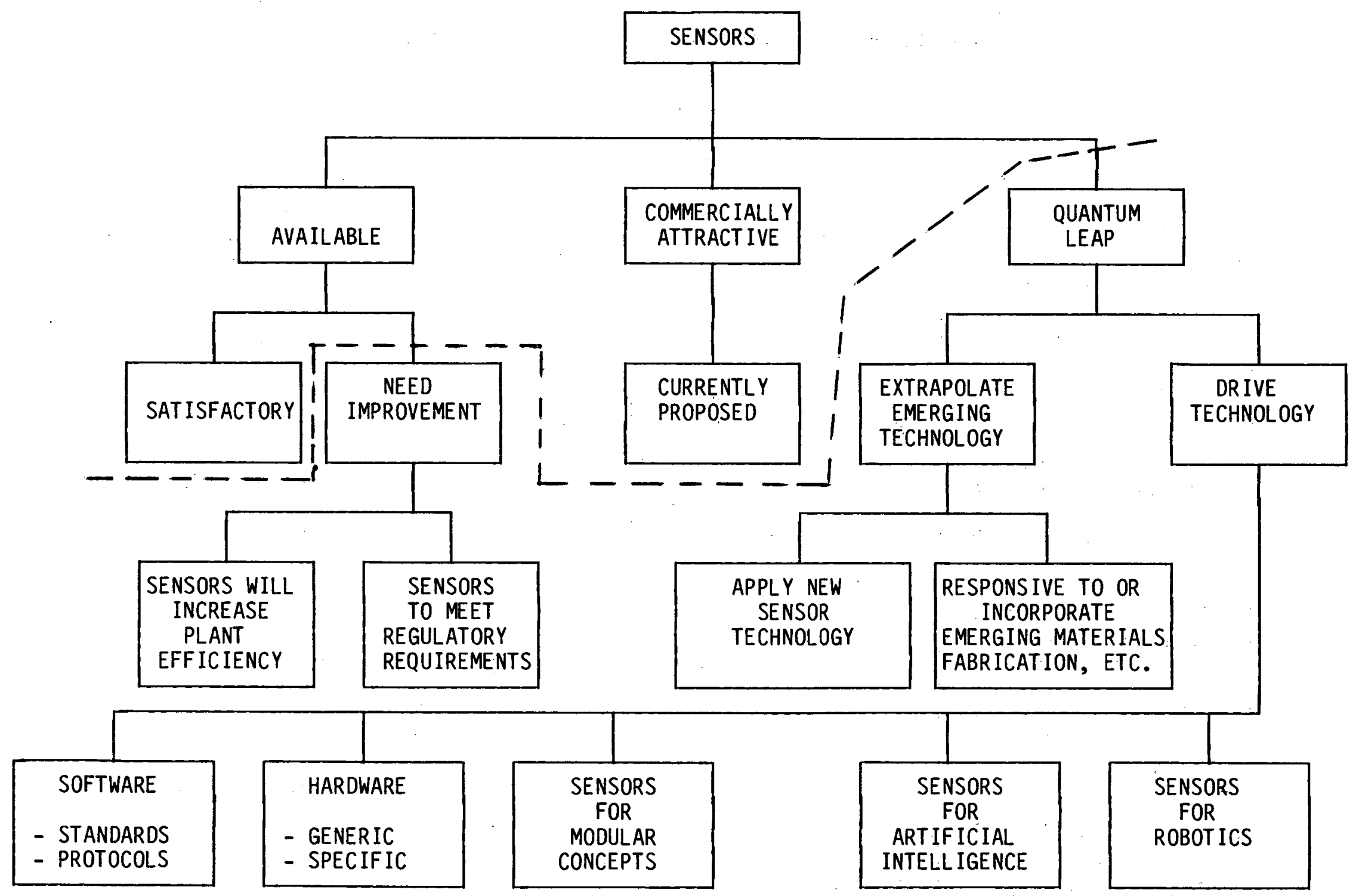




\begin{tabular}{|c|c|c|c|c|}
\hline SENSOR TOPICS & $\begin{array}{l}\text { APPLY OR } \\
\text { MONITOR } \\
\text { ON-GOING } \\
\text { PROGRAMS }\end{array}$ & $\begin{array}{c}\text { EXISTING } \\
\text { TECHNOLOGY } \\
\text { NEEDS TO } \\
\text { BE OPTIMIZED }\end{array}$ & $\begin{array}{c}\text { NEEDS NEW } \\
\text { DEVELOPMENT }\end{array}$ & $\begin{array}{c}\text { BENEF ITS OF PERFORMING } \\
\text { THIS WORK }\end{array}$ \\
\hline $\begin{array}{l}\text { (A) Advanced Technology } \\
\text { 1. Advanced Sensors and } \\
\text { Signal Processing } \\
\text { 2. Fiber Optics } \\
\text { (B) Plant Life Extension } \\
\text { 1. Residual Life } \\
\text { 2. Leak Detection } \\
\text { 3. In-Service Inspection } \\
\text { (C) Process Parameters } \\
\text { 1. Temperature } \\
\text { 2. Pressure } \\
\text { 3. Flow } \\
\text { 4. Level : } \\
\text { 5. Radiation } \\
\text { 6. Coolant Chemistry }\end{array}$ & $\begin{array}{l}X \\
X \\
X \\
X \\
X \\
X\end{array}$ & $\begin{array}{l}x \\
x \\
x\end{array}$ & $\begin{array}{l}x \\
x \\
x \\
x \\
x\end{array}$ & $\begin{array}{l}\text { Cost reduction and } \\
\text { reliability improve } \\
\text { Cost reduction and } \\
\text { eliminating of EMI } \\
\text { effects } \\
\text { Cost avoidance } \\
\text { Improve reliability } \\
\text { or safety } \\
\text { Achieve rated power } \\
\text { Info validation } \\
\text { Cost reduction }\end{array}$ \\
\hline
\end{tabular}

TABLE I-1 NUCLEAR POWER PLANT SENSOR TECHNOLOGY NEEDS 


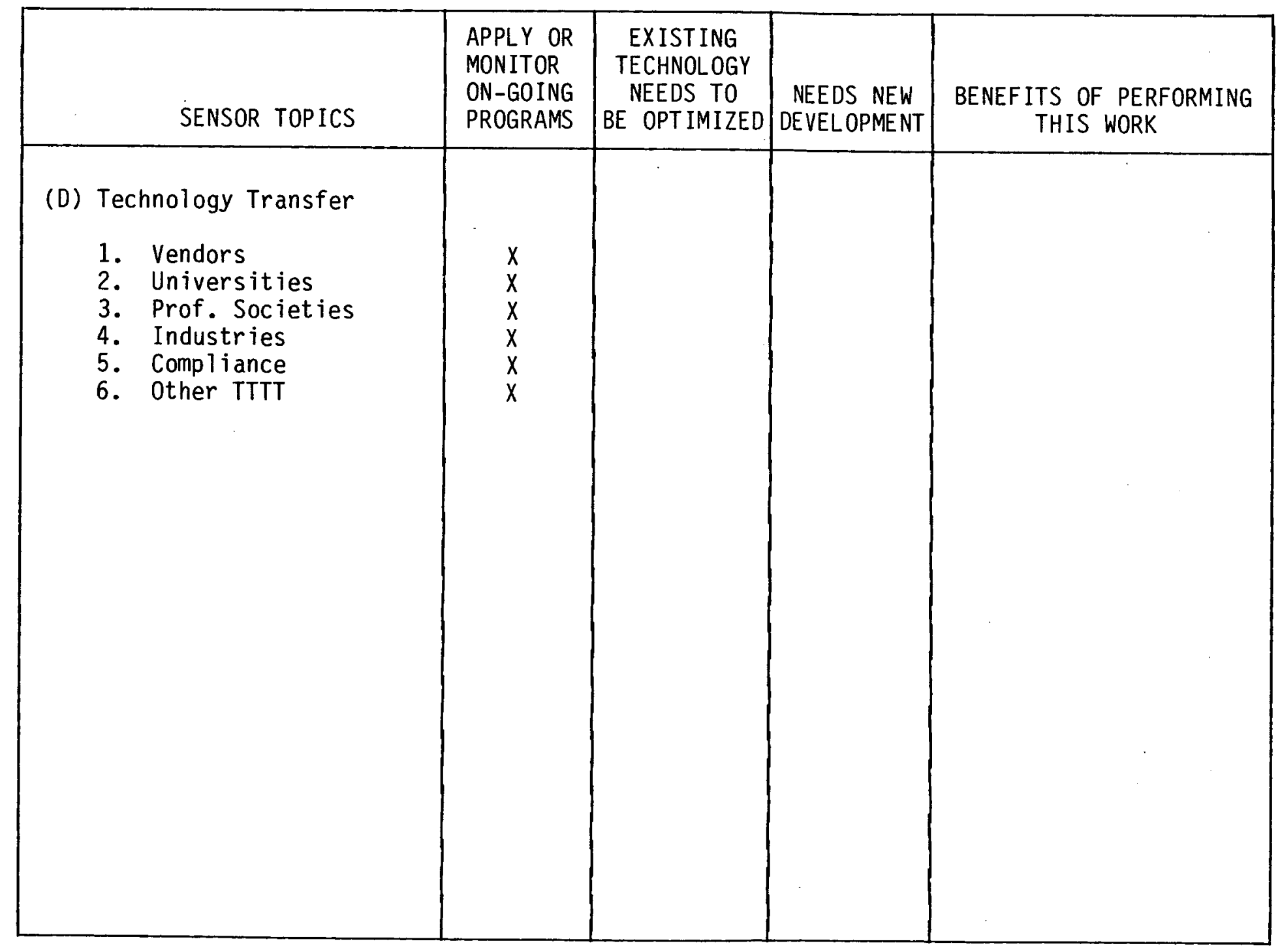


II. TASK TEAM CHARTER AND MEMBERSHIP

\section{A. Charter}

This task team will evaluate the state-of-the-art in sensor development and identify any activities required for application to the nuclear power generation industry of the future. Several aspects of the subject will be approached simultaneousiy:

1. Evaluate and assess the application of the state-of-the-art sensors available today and sensors that are being developed.

2. Forecast the future of sensor development and evaluate which sensors will be developed by other industries regardless of future nuclear power plant needs. Identify which of the sensor developments should be tracked for direct application or modification to meet future nuclear power plant needs.

3. Outline a program for developing new sensors or adapting existing sensors for application to computer technology developments projected for future nuclear power plant operations, maintenance, . protection and inspection. This program will be defined in terms of specific development needs with associated costs and schedule maximizing the use of existing capabilities. 
B. Membership of Sensors Task Team

$\underline{\text { Name }}$

Edward E. Purvis, III

Manager

Sensors Task Team

Dennis N. Elliott

Coordinator

Sensors Task Team

R. (Dick) W. Alliston

Feryl L. Fletcher

David Greene

David 0. Lanning

\section{Address}

U. S. Department of Energy Office of Breeder Demonstrations Projects Washington, D.C. 20545

Westinghouse Advanced Energy Systems Division

Box 158

Madison, Pennsylvania 15663

Rockwell International

Rocketdyne Division

6633 Canoga Avenue

Canoga Park, California 91304

ETEC

Box 1449

Canoga Park, California 91304

GE - NSTO

175 Curtner Avenue, M/C 238

San Jose, California 95125

Massachusetts Institute of Technology

Department of Nuclear Engineering

77 Massachusetts Avenue

Cambridge, Massachusetts 02139 
B. Membership (Continued)

Name

Les C. Oakes

A. C (Paul) Raptis

R. Vittal Rebbapragada

Bill Ritter

\section{Address}

Oak Ridge National Laboratory 3500 Building

Oak Ridge, Tennessee 37831

Argonne National Laboratory

9700 South Cass Avenue

Argonne, Illinois 60439

Burns and Roe, Incorporated

800 Kinderkamack Road

Orade 11, New Jersey 07649

Westinghouse Hanford Company

Post Office Box 1970, W/F 36

Richland, Washington 99352 


\section{TECHNOLOGY EVALUATION}

A. Advanced Technology

1. Advanced Sensors and Signal Processing

a. Objective

Evaluate and assess the combination of the latest semi-conductor, optoelectronic and component reliability technologies with traditional transducer technology to provide smart sensors featuring signal processing to enable inherent data validation, fault tolerance, and diagnostic pattern recognition.

b. Background

Plant outage data and Licensee Event Reports (LER) for nineteen nuclear power plants were reviewed recently for EPRI (Refer ence 1). The objective was to identify which instrumentation or electrical component should be enhanced to increase plant availability, and increase life of the plant by reducing stresses associated with plant trips. About $30 \%(8,000)$ of the LER's were classified as instrumentation or electrical events. A total of $320 \mathrm{plant}$ outages, totaling 34,169 hours were due to instrumentation and electrical equipment problems.

Maintenance and calibration of sensors systems to meet regulatory requirements is very expensive. Drift can occur within a few days on some sensors and is a major contributor to this calibration problem. The ability to make an in-situ calibration would provide immediate reduction in lifetime sensor system cost, and lead to reduction in personnel radiation exposures.

The military and NASA have achieved high reliability of sensors and signal processing electronics by qualification, over-stress and production acceptance tests. Currently, components, which 
are classified as safety Class IE in nuclear power plants, are required to be qualified (which includes over-stress tests); this qualification also requires that the qualified production components be identical and traceable to the tested component. Significant improvements in component reliability can be obtained by requiring non-class IE instruments used inside containment to be qualified to non-accident conditions and production acceptance tested. This technique will also reduce maintenance cost and annual man-rem exposure.

There is a growing abundance of silicon implemented signal processing algorithm functions such as coherence, cross correlation, array processing and simulation models. Add to this a continual significant reduction in cost for performing such functions, and very sophisticated signal processing becomes feasible throughout the plant. Significant cost benefits will result from these preventative diagnostic systems, provided quantitative data and/or specific directions for correction are displayed to the operator. Significant software development cost reductions can occur due to the use of generic programs.

A high degree of standardization of sensors is desirable, preferably to professional society standards (i.e.; IEEE, ISA, etc.). Standardization can be achieved through participation on standards committees. This will aid in lowering sensor costs.

\section{c. Strategy}

The long range focus will be on in-containment parameters and those which directly contribute to the plant protection system. Initially the full requirements for the sensor/data manipulation chain will be formulated and the generic blocks defined to meet the majority of the needs. It is anticipated that two or three generic VLSI circuits will cover $95 \%$ of the signal processing pattern recognition, data validation, self-diagnosis of sensor/ process faults, and electronic calibration needs. The chips will 
be designed using technology for high performance and low power requirements. Redundancy and fault tolerant technology will be an integral part of design. To remove the requirement for power supply to the chip designs will be evaluated with an integral supply, such as photovoltaic. Testing to demonstrate the value of these advanced sensors will progress from demonstration in test reactors and non-safety $\mathrm{plant}$ systems to the prototypic environment of parameter measurement for input to the plant protection system.

Determine the current state-of-the-art of diagnostic and model simulation techniques being used, and their deficiencies. Define the impact that quantitative measurement and operator action threshold definition would have on the current techniques. Quantify the potential for savings. Based on this review, attempt to identify generic problems in signal identification and quantification and propose appropriate development.

d. Problem Definition

Power plant instrumentation maintenance is currently manpower intensive. Fault tolerant, self-validating and possibly selfcalibrating sensors will reduce these costs. Approximately $30 \%$ of License Event Reports from current nuclear power plants (in the period 1980-1982) were classified as instrument, control, and electrical component failures.

Many of the current nuclear power plant diagnostic techniques are essentially qualitative and based on operator judgment. These diagnostic techniques could be significantly improved by quantification of the data to provide a better basis for operator action. 
e. Tasks

- Define requirements for smart sensors based on current practices. Integrate these requirements with future developments; such as providing symbolic output to interface with artificial intelligence machine. Hold design review with appropriate external team. Assess the current state-of-art signal diagnosis systems; their strengths and deficiences. Review existing and proposed signal processing chips and board level products.

- Prepare procurement specifications for VLSI/sensor chips after discussion with potential suppliers and users. Place orders for chips.

0 Test prototype chips and modify the design if required.

o Purchase and test combined chips and sensors.

- Field test as individual sensors, then as a sensor system in test reactors, non-safety systems and eventually prototypic power plant safety related systems.

- Maintain awareness of chip and sensor developments throughout the program with the objective of precluding negative impacts from obsolesence.

- Prepare reports and papers for technology transfer and foster transfer of information by teaming with utilities to define needs and perform qualification testing. 
2. Fiber Optics

a. Objective

Evaluate and assess incorporating emerging fiber optics technology into sensor systems for nuclear power plants to: (1) use light energy as the source of primary sensor power, (2) measure parameter magnitude, convert to a light signal and transmit to local area network (LAN) or data highway; and (3) demonstrate performance of the required functions in an operating nuclear plant environment.

b. Background

Electromagnetic interference (EMI) has caused sensor and signal problems which are difficult to analyze and solve. Power plants typically utilize numerous pieces of equipment which generate or propagate EMI energy. The increased use of computers and microprocessors for instrumentation and control systems will increase the potential susceptibility of these systems to EMI, thus causing such undesirable effects as spurious alarms, and errors in signal parameter measurement.

The use of fiber optic transmission systems is an available technology that is gaining acceptance in the communications and computer industries. The use of fiber optics eliminates the need for wire conductors, thereby eliminating conduction and radiation of electromagnetic energy. In addition, radiation hardening and elimination of corrosion make them environmentally compatible for long term use. Literature searches and meetings with equipment manufacturers indicate that development of fiber optic drives and receivers will accelerate significantly during the next decade. However, there is no indication that these developments include applications for nuclear power plants where there is a harsh radiation and temperature environment. 
c. Strategy

Review developments of fiber optic systems and components in the USA and foreign nations and select design concepts for nuclear applications development. Develop fiber optics by (1) establishing requirements, (2) evaluating current state-of-the-art and establishing areas requiring modifications and development; (3) designing, developing and fabricating associated optical electronics; (4) conducting laboratory testing and development to demonstrate operability when exposed to a nuclear power plant environment; and (5) conducting an extended duration test program in an operating plant. Nuclear test facilities directly amenable to fiber optic system test programs are FFTF, EBR-II and HFIR.

d. Problem

We need to define how to apply fiber optics technology to the nuclear power plant industry to take advantage of the rapid innovation and research in this area. Current cabling systems are susceptible to EMI and ground loop currents which create errors in data transmission and spurious alarms. Electrical cabling is significantly more expensive than fiber optic cabling and contributes significantly to plant construction, operation and maintenance costs.

e. Tasks

There are three major tasks needed in this area:

(1) Develop a fiber optic transmission system for nuclear applications as outlined below:

o Determine performance capabilities of various materials and configurations, currently available, under adverse radiation and temperature environments. 
- Determine other candidate materials and configurations which potentially offer improved performance, select and acquire these materials and configurations, and evaluate the candidate designs under adverse environmental conditions. Also to be evaluated are handling characteristics, terminators, connections, leakage and light access.

- Evaluate improved performance capabilities against anticipated requirements. If necessary, identify additional development requirements.

- Prepare encompassing standards, parameter lists and documentation.

(2) Develop optoelectronic integration circuit functional and performance requirements with the following task elements:

- Establish the quantity of circuit configurations required and the features desired for each. Features anticipated to be incorprated are: (1) light energy conversion to electrical energy to provide primary power, (2) analog to digital conversion, (3) digital storage and conditioning, (4) parallel to serial conversion, (5) voltage to frequency and frequency to voltage conversions, (6) optic drivers and receivers, (7) fault tolerance, (8) "smart" or self-calibration capabilities, and (9) protocol conversion.

- For each circuit configuration, establish desired performance limits and environmental parameter ranges.

- Evaluate potential material and process configurations, select candidates for testing, purchase candidate circuits and conduct performance and environmental tests. 
- Select candidate circuits for design modification (upgrading of performance levels and tolerance to environment), obtain improved configurations and retest.

- Evaluate improved performance capabilities against anticipated requirements. If necessary, identify additional development requirements.

(3) Select a host nuclear operating plant, such as FFTF and EBR-II, and test fiber optic data highway and local area network and selected sensor systems in actual nuclear environments and service conditions. Included are the following task elements:

- Select and acquire typical sensor systems for fabrication and installation into an operating plant. Typical parameters which are to be included are flow, level, pressure, temperature and valve position.

- Prepare installation, operations and maintenance documentation.

- Install sensor systems into host facilities (installations should include locations in typical service environment).

- Conduct tests over an extended time period to demonstrate performance, reliability and maintainability.

- Evaluate test program data and determine what sensor design improvements are needed.

- Incorporate design improvements into the installed sensor systems and continue with testing and data evaluation. 
B. Plant Life Extension

1. Residual Life Measurement

a. Objective

Evaluate and assess technology for sensing structural integrity in nuclear applications. While many of the techniques of interest are not typically thought of for sensing applications, the approach here is to solve specific problems in the nuclear industry to take maximum advantage of developing technologies. Emphasis will be on measurements that would help to justify plant life extension.

b. Background

There are a multitude of techniques to measure material behavior. Specific topics are as follows:

- Magnetic properties correlation to mechanical properties

- Fatigue damage and wear

- In-situ chemical analysis

- Load and deformation characteristics--displacement, strain, force, etc.

A serious problem has been experienced in evaluating the residual ductility in reactor vessels with long service lives. As ductility decreases there is an increasing potential for material damage during transient conditions. If one could develop a correlation between ductility and magnetic measurements this could form the basis for a very useful technique to extend the life of existing plants. The economic incentive to extend $p l a n t$ life is 
obvious and could offset the technical and institutional challenges of qualifying plants for continued service. This theme can be applied to each of the topics listed above with some examples as follows:

- Fatigue damage accumulation and wear tend to be design limiting mechanisms. Development of in-situ methods of evaluating these damage mechanisms have been studied and need to be applied to the application of plant life extension.

- In-situ chemical analyses has been studied using tunable diode lasers and infrared spectroscopy with acousto-optic tunable filters. Nuclear applications would include monitoring gaseous environments for detection of failures. Since incipient failures could be detected, this type of technique could be used to support plant life extension while still guaranteeing safety.

- Load and deformation characteristics have been studied using many techniques. Those of interest in this work would enable field measurements (such as those with strain gages) to help support plant life extension.

c. Strategy

Evaluate design limiting conditions in existing plants. Develop sensing techniques to measure material behavior at critical plant locations to support plant life extension. A key area of this program will be to work closely with regulatory agencies to develop evaluation criteria for plant life extension. To this end it is anticipated that there would be a continuing interface with NRC during this program. Development of this strategy will include a cost benefit study to determine the highest priority areas of work. 
d. Problem Definition

The basic problem to be solved in this program is to determine how we can justify extending existing nuclear power plant lives by proving continued structural integrity of the plant.

e. Tasks

- Survey the field of residual life assessment with emphasis on measurement of material behavior. Develop a priority of design limiting problems and cost benefit study of promising areas for measurement.

- Establish criteria for acceptance by regulatory agencies for justifying plant life extension.

- Develop selected sensor applications and demonstration in small research reactors through actual plant studies. 


\section{Leak Detection}

a. Objective

Evaluate and assess improved coolant detection, leak rate measurement and leak location instrumentation for existing and new plants. These measurements are required for safe operation of steam generators in LMR's and the "leak before break" approach for all nuclear power reactors.

Sensors to detect leaks from high pressure piping systems are expected to have an important role in Light Water Reactor safety systems. The objective of leak-before-break (LBB) sensor systems will be to give prompt indication of the initiation of leaks and their location, so that the nuclear plant supervisor can make a rapid and accurate evaluation of the seriousness of the leak, and a decision on repair.

b. Background

Many existing nuclear power plants depend upon sump pump water flow rate as their sole means of detecting breaches in the coolant boundaries. This approach is effective for large leaks; however, more emphasis is being placed upon earlier detection (detection of the leak in its infant state). With earlier detection it is also essential to consider methods of leak location, because the leak site may not be readily apparent by visual inspection.

The Nuclear Regulatory Commission General Design Criteria for nuclear power plants has required that systems and equipment which are needed to perform safety functions following a pipe system accident must be protected from the mechanical effects of the rupture, such as pipe-whip and missiles, resulting from the rupture. The pipe restraints to fulfill the criteria from small pipe through the large (greater than 30 inches in diameter) 
reactor coolant piping are massive, clutter the containment and other pipe spaces, and place undue burdens on the building design loads. Recently, the NRC has found that the probability of reactor coolant pipe rupture is so low that the reactor coolant pipe restraints will no longer be required, provided the utility shows that the piping meets the new LBB criteria. In effect, the new approach is based on the expectation that this class of piping will leak long before it will break catastrophically. Instrumentation to detect the leakage quickly will be a particularly important safety feature in the new LBB criteria. This change in licensing criteria makes it necessary to do a careful review of leakage sensor speed of response, sensitivity, and reliability, as well as the new requirements in order to provide suitable systems.

A survey of literature related to this subject (see references) indicates that acoustic leak detection (ALD) techniques have become the favored area for development in recent years. Many existing plants utilize the objective of the ALD systems to detect the occurrence, and hopefully location, of small leaks which may be precursors to major pipe breaks. These efforts include construction of an ALD test facility at Argonne National Laboratory.

c. Strategy

The general approach is to review the LBB criteria for reactor coolant piping, and to study how these criteria might be applied to smaller size piping (in the range of 2 inches to 30 inches in diameter) in order to establish the expected leakage rates from these piping systems in the event of failure. Specific design approaches will then be developed for the different sizes of pipe. The performance of existing leak detection systems will be judged against requirements. If performance improvements are necessary, we plan to recommend new methods of detection which could offer better sensitivity, reliability, or speed of response. 
We will then be able to make recommendations on engineering application of available sensors for this service, or on development which may be necessary to meet the requirements. Existing programs at universities will be evaluated for integration with this program.

d. Tasks

- Establish the requirements for leakage sensors.

- Survey existing sensors.

- Search for improved methods of detection; and evaluate and recommend a course of engineering application or development for leak detection in both existing and future plant piping systems.

- Continue on-going acoustic leak detection development programs for determining coolant leak detection and location systems. This includes evaluation of steam generator acoustic leak detection system and determining ability to meet system requirements. 


\section{In-Service Inspection}

a. Objective

Evaluate and assess emerging technologies for loose parts monitoring and pressure boundary weld examination systems.

b. Background

There are deficiencies with current systems. However, there are program in progress which may solve most of the deficiencies. These systems are currently in use and with continued use for current BWR and PWR plants, it is expected that developments will continue over the next decade.

c. Strategy

Monitor existing and any new programs and continue to evaluate emerging technology incorporation.

d. Tasks

- Participate on the ASME subgroups working on a loose parts monitoring standard and other technical committee to monitor progress of standards development.

- Monitor sensor technology development and implementation for in-service inspection systems and provide recommendation for additional development when and where needed.

The commercial competition in this area is so aggressive that no funding is needed to spur development. 


\section{Process Parameters}

\section{Temperature}

a. Objective

Evaluate and assess the application of temperature sensors in the nuclear power industry and identify any development needs.

b. Background

The primary means of measuring temperature in nuclear reactors has been chromel-alumel thermocouples and resistance thermometers. Both types are used in control systems whereas plant protection and performance systems have almost always utilized resistance thermometers for the primary sensing element.

Implementation of existing technology could improve both the accuracy and range of the fundamental sensing elements and the methods whereby regulatory and operational requirements for accuracy and time response are periodically verified. Furthermore, new materials are now available that are capable of operating well above the normal range of chromel-alumel which is the usual material of choice for reactor grade thermocouples. This material can be employed in post accident monitoring systems for operation up to $2200^{\circ} \mathrm{C}$. Systems having better inherent accuracy than thermocouples and resistance thermometers may be used to economic advantage where technical specification limits can be maximized during steady state operation to improve generating capacity.

Other techniques for temperature measurement, such as thermistors, radiation, pyrometers, açoustic time domain reflectometry, and the gamma hodoscope have not been used extensively in nuclear reactors. However, computer technology has made possible application of these devices in balance-of-plant uses where nonintrusive measurements can lead to better system integrity. 
c. Strategy

No basic technology development is needed in addition to existing programs. Feasibility for most of the technology needed to achieve temperature measurement improvements has been demonstrated. To implement this technology in the nuclear power industry requires only development of methods of modifying the existing laboratory models to systems compatible with power reactors. Relevant information may be generated by the various professional committees especially the IEEE, ISA, ASTM, and others.

d. Problem Definition

Regulatory requirements dictate the necessity for periodic verification of accuracy and time response of sensors used in the plant protection system. The method most of ten used to meet the accuracy requirements is to remove the sensors from service and calibrate them using conventional laboratory methods. 'In-situ calibration could lead to improved performance by eliminating the necessity of removing the units from the process stream. Removal and replacement of sensors incurs risk of damaging the units by improper handling, exposing the maintenance staff to increased man-rem, and introduces the possibility of improper reconnection.

Measurement of reactor temperature beyond design basis conditions is desirable in both current and future plants. The desirability for such high temperature measurement capability was demonstrated at TMI-2. Recent work to characterize reactor core behavior during safety tests led to development of new thermocouples. Specifically, thermocouples have been successfully developed to operate to $1800^{\circ} \mathrm{F}$ in steam for fuel cladding temperature measurements and to $2200^{\circ} \mathrm{F}$ for reactor fuel centerline temperature measurements. Current efforts in high temperature thermometry include development of materials and components for stable thermocouple operation up to $2800^{\circ} \mathrm{F}$ with $+2 \%$ accuracy. Further 
development and demonstration of such thermocouples could lead to an industry standard with sufficient $r$ ange to cover both normal and off-normal or beyond-design-basis conditions. The range of $2800^{\circ} \mathrm{F}$ is adequate to cover beyond-design-basis accidents for all current reactor concepts including the modular HTGR's.

Systems capable of greater accuracy, such as absolute thermometers, may be useful to improve performance by allowing the plant to operate at rated power levels. Estimates of 10-20\% increases have been given.

e. Tasks

No development efforts are needed in addition to existing programs. There is a need to keep aware of developments in temperature measurement occurring in other industries with a view to transferring that technology to the nuclear industry. Typical examples of topics in this category are as follows:

0 There is an extensive effort in radiation thermometry and many manufacturers are active in this market. These devices could be used for diagnostics and should be considered for application in nuclear power plants. Design modification may be needed for integration of this technology.

- Development of tube skin thermocouple shows excellent promise. This provides an efficient and economic way to install temperature sensing devices on metal surfaces of pipes and tubes.

- Monitoring of extended range thermocouples capable of tracking accident conditions to higher levels than was possible in TMI -2 .

- Monitoring of sensor in-situ calibration techniques to reduce the time required for these operations and to enhance safety. 
- Monitoring of improvements in sensor accuracy to permit higher power operation. Calibration uncertainties due to drift and radiation exposure are traditional problems with thermocouples and resistance thermometers. Absolute thermometers, such as the Johnson noise thermometer, could substantially reduce the temperature measuring uncertainties and eliminate aging and radiation drift. In addition, such thermometers could allow measurements to be made in higher temperature (above $1000^{\circ} \mathrm{C}$ ) environments found in gas-cooled reactors.

- Developments in acoustic thermometry could be used for temperature profile measurement in the core. This requires an intrusive device, however, it is easy to implement and does not require calibration.

- The work done on the gamma hodoscope should be reviewed to evaluate the applicability to the nuclear industry. 
2. Pressure

a. Objective

Evaluate and assess pressure measurement systems presently utilized in operating nuclear power plants and identify any development needs.

b. Background

A recent EPRI report (Reference 1) indicates that pressure measurement systems are a significant contributor to outages at operating nuclear powers. The reported failures can be categorized into the following areas: 1) sensor failures, 2) sensing line failures and 3 ) penetration failures. Discussions with the utilities indicate that many of the installations do not use existing state-of-the-art instruments and that the sensing lines installation techniques have not been optimized.

c. Strategy

No development effort is needed in addition to existing programs.

d. Problem Definition

Pressure measurement system outages in existing nuclear power plants could be improved by installing state-of-the-art commercially available systems. Sensing line problems could be reduced by eliminating as much sensing line as possible and optimizing all sensing lines which cannot be eliminated.

e. Tasks

No basic development is needed at this time. Presently available technology should be adequate for existing plants. New technology being developed for other business segments should be 
monitored and continuously evaluated to insure pressure measurement system compatability with signal transfer requirements defined for new plants. 


\section{Flow}

a. Objective

Evaluate and assess existing technology in single phase and multiphase flow and examine its applicability to nuclear power plants. This will include the evaluation of commercially available sensors, as well as sensors under development by industry, universities and national laboratories.

\section{b. Background}

Measurement of flow (single phase or multiphase) has received considerable attention in recent years at universities and national laboratories. Instrument manufacturers have concentrated on conventional single phase instrumentation. The commercially available sensors can be categorized as: (a) intrusive i.e., penetrates the flow stream (head-type, dragtype, segmental wedge and a variety of impedence probes) and (b) non-intrusive i.e., do not penetrate the flow stream (acoustic, optic, electromagnetic/microwave and nuclear).

At this point mostly intrusive sensors are used in nuclear plants. Discussions with TVA, Consumer Power, DuPont and others, have indicated that intrusive sensors can create plugging in lines and need frequent calibrations. Discussions with TVA and Consumer Power have also indicated that a more accurate, reliable and repeatable flow measurement would be desirable to improve their calorimetric calculations and therefore help achieve their maximum rating. Measurement of water/steam flows and void detection were mentioned as two measurements where improvements are needed. This information would be useful to provide a data base for design of future nuclear powerplants. Consolidated Edison has reported through EPRI that the modified Westinghouse leading edge acoustic flowmeter has provided good accuracy and dependability. 
c. Strategy

No development effort is needed in addition to existing programs.

d. Problem Definition

Flow instruments are needed that have $1 \%$ accuracy (or better), low drift, good repeatability and easy calibration with high reliability.

e. Tasks

While no new development is needed in addition to existing programs there is a need to monitor the following topics:

o Testing of the Westinghouse flow meter in existing power plants.

- Development of the upstream/downstream transit time flow meter for single phase flow.

- Development of active acoustic cross correlation for water inlet or steam/water flows.

o Development of the acoustic Doppler for void monitoring. 
4. Level

a. Objective

Evaluate and assess liquid level measurement systems which meet plant requirements in terms of accuracy, reliability, maintainability and compliance with regulatory guides, codes, standards and plant technical specifications. This will include evaluation of commercially available systems which can be adapted to meet the environmental requirements and new technology sensors presently under development by industry, universities or national laboratories.

b. Background

The absence of a means to measure the coolant level in the reactor vessel led to control room confusion and was a major contributor to the Three Mile Island accident in March 1979. Since this accident, much attention has been focused upon this problem. The general consensus derived from the concentrated study was that instrumentation to monitor subcooling margin, core exit temperature and reactor coolant inventory is required for the safe operation of pressurized water reactors (PWR's). The requirements have been incorporated into "Three Mile Island Plan II F.2" of NUREG-0737. Two major U.S. reactor vendors-Westinghouse and Combustion Engineering--offer coolant level measurement systems which have NRC acceptance. The Westinghouse system employs a differential pressure measurement between the reactor head penetration and the reactor coolant inlet nozzle and a differential measurement between the reactor coolant inlet nozzle and the bottom of the reactor vesse1. The Combustion Engineering system uses a thermocouple rake consisting of both electrically heated and unheated thermocouple junctions. The temperature difference between the heated and unheated thermocouple junctions is larger when the junctions are in a steam region than when the junctions are located below the water level 
because of the difference in heat transfer. The rake is inserted in a split separator tube to enhance separation of the reactor coolant into steam water regions in the area surrounding the rake.

Industry, both in the U.S. and overseas, and the national laboratories and universities continue to search for improved water level measurement techniques. Some of the more promising of these are:

1. Ultrasonic using wave guides -- ORNL

2. Pulsed Neutron

-- ANL, Penn State University

3. Neutron Detectors

-- Penn State University, INEL

4. Gamma Thermometers

-- $\quad$ Scandpower-FRG, Hitachi-Japan

5. Displacer Float

-- Czechoslovakia

6. Conductivity

-- INEL

7. Gamma Hodoscope

$--\quad$ ANL

8. Ultrasonic Using Impedance Matching

$--\quad$ ANL

9. Microwave

-- University of West Virginia

Many different measurement techniques have been proposed and tested for measuring liquid sodium level in liquid metal cooled power reactors. Four different techniques have proven to be useful for different applications. These are: (1) differential pressure; (2) displacer float; (3) continuous inductive; and (4) point inductive. Of these the continuous or point inductive are most suitable because they $c$ an be removed and replaced without breaking the coolant boundary. Commercial sources for these transducers are available in the United States, Great Britain, Federal Republic of Germany and Japan. 
c. Strategy

No development effort is needed in addition to existing programs.

d. Problem Definition

Problem areas can be broken into two areas for LWR reactors:

- Reactor coolant level problem areas are: a) large density change of water with temperature over the operating $r$ ange; b) relatively small change in density between saturated water and steam at operating condition; 3 ) mixed phase conditions and 4) frothing

- Balance of plant--large diversity of existing instruments, each with its own set of installation problems and operating limitations.

e. Tasks

While no new development is needed for existing nuclear power plants it would be desirable to monitor the developments in other industries with a view to application in future nuclear reactors or re-instrumentation of existing plants. 
5. Radiation

a. Objective

Evaluate and assess radiation monitoring sensors which meet safety requirements and permit optimal power plant operation.

b. Background

Measurement of ex-vessel neutron flux is fundamental to nuclear reactor operation. In-core flux monitoring is also common and general area radiation monitoring is required in a nuclear facility. Equipment for general area monitoring is adequate, although some evidence exists that calibration is too expensive and time consuming.

According to a recent EPRI funded study, (Reference 1) reactor radiation monitoring sensor problems accounted for only 3 percent of License Event Reports issued for 19 plants over a 3 year period. Radiation sensor reportable events were due to either end-of-life or moisture-related problems. Plant outage events were associated with in-core neutron sensor problems. Better protection of cables and connectors should resolve the other few known problems.

Opportunities do exist to develop new radiation sensors for incore and ex-vessel applications. Specifically, development of a radial gamma thermometer (RGT) as a local power indicator in fuel bundles could eliminate the need for fission counters in-core. Alternately, a prototype of a position-sensitive fission counter (PSFC) for in-core monitoring which requires only a single vessel penetration, was recently introduced by Oak Ridge National Laboratory (Reference 2). An ultrahigh-sensitivity fission counter for ex-vessel, source range applications was also recently developed by ORNL (Reference 3 ). Development work is now nearing completion for high temperature $\left(650^{\circ} \mathrm{C}\right)$ fission 
counters for application in LMR's. This detector would eliminate the need for cooled thimbles such as those used in FFTF. One area for technology transfer is connectors and high temperature cables for flux sensors. The capability to manufacture high temperature cables for flux sensors has not been demonstrated by private industry.

c. Strategy

Since few problems with current sensors are being experienced by commercial plants, no new basic development is needed.

d. Tasks

While no new developments programs are needed, the following topics are of interest in radiation monitoring:

- Monitoring operating $\mathrm{plants}$ for negative trends in existing radiation monitoring sensor performance.

- Continuing development of fission counters for in-core applications.

- Transferring the technology for flux sensor connectors and high temperature cables to private industry.

o Monitoring for development of fiber optic radiation sensors which could be utilized in nuclear power plants. 
6. Coolant Chemistry

a. Objective

Evaluate and assess coolant chemistry monitoring in existing and future nuclear power plants.

b. Background

Water chemistry must be controlled in all power plants utilizing a steam cycle for the conversion of thermal power to mechanical power and subsequently to electrical power to insure maximum service life of the materials in contact with the water/steam. on-line water chemistry instrumentation presently exists for the contaminants being encountered. However, their stability is such that frequent grab samples must be taken for laboratory analys is to verify and adjust the instruments and some sensors have required frequent replacement. Thus, these measurements add significantly to the plant operating expenses.

Sodium hydrogen and oxygen concentration meters presently exist, but there are no commercial sources for these meters in the United States. A commercial source for the oxygen meter solid electrolyte which fits existing meter housings and with extended operating life would be desirable for any future sodium cooled reactors.

Moisture monitors for HTGR's are required to prevent excessive oxidation of the reactor materials.

c. Strategy

No new development programs are needed. 
d. Problem

Requirements for on-line water, sodium and helium chemistry monitors suitable for effective power plant operation are not sufficient to attract adequate company funded research and development funds. Industrial companies' projections of new plant requirements and existing plant replacements are not adequate to invest their limited research funds.

e. Tasks

While no new development programs are needed, the following topics are of interest in coolant chemistry:

- Review of other business segment requirements and research and development projects. This review should include foreign countries, universities and NBS activities in the areas of water chemistry instrumentation.

- Insure maximum utilization of technology transfer by selecting the best emerging water chemistry instrumentation, foreign or domestic, and verifying performance in an operating power plant.

- Select a company or national laboratory to manufacture sodium oxygen concentration meter solid electrolyte.

- Continue MIT research on helium moisture monitors. 


\section{Technology Transfer}

Sensors are being developed in many industries for a wide variety of applications. One aspect of technology transfer is to ensure that the technology developed in other industries is transferred to the nuclear industry when appropriate. To this end there is a need to maintain contacts with: the vendors manufacturing sensors, universities, professional societies and other industries. The purpose of these contacts is to apply any lessons learned from other industries to improve nuclear power cost or reliability. To some extent the first need is to maintain an awareness of what is being developed in the other industries. The current DOE program on sensors development for nuclear power plants does not cover the establishment of this technical awareness.

Another aspect of technology transfer is related to using any data or results from DOE programs related to sensor development. It can be argued that the DOE role in sensor development should be limited to developing basic technology which is subsequently applied by other parts of the nuclear industry; e.g. sensor vendors, reactor manufacturers, EPRI and the utilities. From this standpoint it is important that no development work is performed without thorough review with the target user (utility or reactor manufacturer). Probably the best way to ensure technology transfer is to have participation by the target user and in this case there are several important phases of development for interface: planning objectives and testing, field testing, qualification to meet regulatory requirements.

With regard to the technology transfer with in the DOE High Technology Initiative program it is very important to transfer between the sensors development and that related to artificial intelligence, robotics and modularization. 
During preparation of this report we had several interfaces with the other task teams and explored their sensor needs. Application of robotics technology needs the following sensors:
- Spatial (Location)
- Infrared
- Force
- Tactile/pressure
- Vision
o Viewing/Lighting
- Collision Avoidance

Most of the above sensors are developed for manufacturing applications and fixed robotic applications. Application of these developments to nuclear industry robotics systems will require a program to perform the following tasks:

- Survey the sensors developed for adequacy to nuclear application.

- Develop a program to qualify the sensors to nuclear environment.

- Identify sensors that are needed unique to the nuclear industry.

- Fund development of sensors by universities and National Laboratories.

The interfaces with Artificial Intelligence and Modularzation are not as clearly defined at this time. The first priority would be to review the program needs from the other task teams and convene separate sessions as appropriate to provide effective interfaces. The interface with artificial intelligence appears to be particularly fruitful in developing advanced control of operating nuclear power plants.

Sensors installed on or attached to nuclear power plant piping or vessels must comply with ASME Boiler and Pressure Vessel Code Section III. In order to be used in Class $1 E$ measurement, or control circuits, a qualification program would have to be initiated. There are no IEEE qualified 
"Advanced Sensor Assemblies" commercially available at the present time. When the sensor is intended to be installed in a nuclear power plant, a quality assurance program must be in place to comply with one of the following programs: ANSI $N 45.2$ Section 2 for Class $1 E$ items, ANSI B31.1 for non-safety items, ASME Boiler and Pressure Vessel Code Section III, Division I, Article NA-4000 for code class items. 
IV. DEVELOPMENTS UNDERWAY AND CONTACTS

Many visits and telephone calls were made to compile information for input to this report. In addition, several conferences were attended by some of the team members to obtain current information, viewpoints and predictions of future developments. These contacts provided a broad spectrum of information in addition to the experience base and information available through the task team member organizations. Highlights of specific contacts made during preparation of this report are summarized below:

University of Florida

Several members of the faculty participated in discussions and tours of various laboratories. The main topics were robot sensors and fiber optics.

DuPont

A visit was made to DuPont, Newark, Delaware to review advanced sensor development in the chemical process industry. Details of this visit are reported in Appendix I. A wide range of topics was discussed including: temperature, pressure transmitters, turbine meter flow measurement, level, digital control, value position indication, etc.

Purdue University

Discussions were held with several members of the Purdue University faculty and laboratory tours were arranged to examine work being performed on fluid mechanics, heat transfer, flow measurement and optical measurement. The principal topic of discussion was temperature measurement and calibration. Details of this visit are reported in Appendix I. 
University of Arizona

Faculty members participated in presentations and discussions on the following topics during a visit to the University of Arizona:

- Development of thermionic circuits for high-temperature applications.

- Development of optical monitoring and 3D image enhancement

- Electromagnetic remote sensing.

- Atmospheric radiation and optics

- Electro-optical instrumentation

- Solar energy and energy management

- Semiconductor device design and analysis

- Image processing, analysis and pattern recognition

Details of this visit are presented in Appendix $\mathrm{I}$.

Argonne National Laboratory (ANL)

Details of a visit to ANL are reported in Appendix I and subsequentiy an ANL representative (Paul Raptis) was appointed to help in the preparation of this report. Topics of discussion during the visit included: acoustic techniques of measurement, fission counters, simulation models, leak detection, flow measurement, temperature measurement, level, fuel failure monitoring and non-destructive examination.

Tennessee Valley Authority (TVA)

The sensors task team met with TVA personnel in Chattanooga to review typical instrumentation problems experienced by the utility industry and the following topics were discussed: feedwater flow measurement, pressure measurement, level, valve testing, installation, in-service inspection, calibration, diagnostics and standardization. 
EPRI Seminar on Safety Control Technology

Two of the team members attended a seminar on safety control technology sponsored by EPRI and, apart from the formal presentations, used the opportunity to explore sensor development needs with EPRI personnel the many utility representatives at the seminar.

Conference on Optical Fiber Communication and Optical Fiber Sensors

A conference on fiber optics technology was attended in San Diego, California, February 11-14, 1985 to help in the evaluation of this topic for development needs applicable to the nuclear industry. A report of this conference is included in Appendix I.

Gas Cooled Reactor Associates (GCRA)

A visit was made to GCRA to review the sensor needs for high temperature gas reactors. The principal topics of discussion were moisture monitors, reactor core temperature measurements, core in-service inspection, and helium diffusion. A report of this visit is included in Appendix I.

Georgia Institute of Technology (GIT)

The Neely Nuclear Research Center at GIT was visited and their 5MW research reactor and chip design CAD system was toured. The main topic of discussion for possible development was the need to relate mechanical properties to magnetic properties for plant life extension studies.

Vendor Survey

An extensive vendor survey was performed and is reported in Appendix I. Topics covered included temperature, pressure, flow, level, radiation. 
Professional Societies

A review of the related professional society committees was performed to establish a list of those committees working in areas that would be of interest to nuclear sensor development. The list of committees is shown in Appendix $I$ and includes about 30 committees or working groups from the following societies ASME, ISA, AIAA, IEEE and ASTM. 


\section{REFERENCES}

1. Field-Hardened Instruments and Electrical Components for Nuclear Plant Applications--Project Planning, EPRI NP-3649, August 1984

2. Position Sensitive Fission Counter for In-Core Flux Profile Monitoring, M. K. Kopp et. al., IEEE Transactions on Nuclear Science, February 1984

3. Ultrahigh-Sensitivity Fission Counter with Transmission Line Electrode Configuration, K. H. Valentine, et. al., IEEE Transactions on Nuclear Science, February 1983 
A selection of papers, articles etc., is listed in this bibliography to provide background references to the reader requiring more information. These references are listed by topic by the order in which they appear in the report. 
Fiber Optics

1. OFC/OFS 1985, OSA/IEE Technical Digest of Conferences on Optical Fiber Communication and Optical Fiber Sensors, February 1985, IEEE Catalog No. 85CH2094-1, Library of Congress No. 84-62007.

2. "Field-Harden Instruments and Electrical Components for Nuclear Plant Applications--Project Planning"; EPRI NP-3649, Volumes 1 and 2, August 1984, SAI.

3. "Optical Fiber Sensor Technology," Thomas G. Giallorenzi, Joseph A. Bucara, Anthony Dandridge, G. H. Siegel, Jr., James H. Cole, Scot C. Rashleigh, Richard G. Priest; IEEE Journal of Quantum Electronics, Vo1. QE-18, No. 4, April 1982, pp. 626-665.

4. "Effect of Low Dose Rate Irradiation on Doped Silica Core Optical Fibers," E. Joseph Friebele, Charles G. Askins, Michael E. Gingerich; Applied Optics, Vol. 23, No. 23, December 1, 1984, pp. 4202-4208.

5. "Wide-Range Fiber-Optic Strain Sensor," Dean C. Marvin, Neil A. Ives: Applied Optics, Vol. 23, No. 23, December 1, 1984, pp. 4212-4217.

6. "Fibre Optical Sensors," T. G. Giallorenzi; New Directions in Guided Wave and Coherent Optics, Proceedings of the NATO Advanced Study Institute, D. B. Ostrowsky and E. Spitz (Editors); Vol. 1, 1984, pp. 225-245.

7. "Applications of Fibre Optics in Sensors," J. E. Donovan, T. G. Giallorenzi, J. A. Gucaro; Electro/81 Conference Record, 88/4/1-14, 1981.

8. "Recent Progress In Integrated Optics," T. Sueta; European Conference on Optical Communication, 1982, pp. 221-225. 
Plant Life Extension

1. Private communication with Ratib Karam, Neely Nuclear Research Center, Georgia Institute of Technology, February 1985.

2. W. J. Baxter et. al., "Gel Electrode Evaluation of Fatigue Performance of Aluminium Components" SAE paper ISSN 0148-7191, February 27-March 2, 1984.

3. W. J. Baxter. "Oxide Films: Quantitative Sensors of Metal Fatigue "ASTM Special Technique. Publication 811, 1983.

4. D. L. Partin, "Single quantum well lead--europium--selenide--telluride diode lasers" Applied Physics letter 45 (S), September 1, 1984.

5. D. L. Partin, "Lead Salt Quantum Well Diode Lasers" GMR-4822, September 19, 1984.

6. K. B. Steinbruegge et. al. "Imaging Spectroscopy: Automated acousto-optic tunable filter infrared analyzers" Proceedings of SPIE (Volume 268) Conference Los Angeles, February 1981.

7. M. J. Murwitz, et. al. "Water Induction Detection System: Field Testing," Conference on Incipient Failure Detection in Powerplants" Lake Bueno vista, Florida, October 1984.

8. C. A. Negin, et al "Extended Life Operation of LWR: Economic and Technical Review", EPRI NP-2418, June 1982. 
Acoustic Leak Detection

1. "Diagnostic System for Primary Circuits of Pressurized-Water Reactors"; J. Liska and J. Majer; Skoda Review (Czechoslovakia) Number 2, pp. 18-21, 1983.

2. "Environmentally Assisted Cracking in Light Water Reactors"; W. J. Schack; Tenth Water-Reactor Safety Research Information Meeting Proceedings, Volume 4, January 1983; CONF-821037, Volume 4, Conference held 10/12/82 in Gaithersburg, MD.

3. "Analys is of Acoustic Leak Detection for Light Water Reactor"; $D$. S. Kupperman, T. N. Claytor, D. Prine, R. Groenwald; CONF-821079; pp. 45-50, International Conference on Inspection of Pressurized Components, held $10 / 12 / 82$ in London, U.K.

4. "Acoustic Leak Detection and Ultrasonic Crack Detection" D. S. Kupperman, T. N. Claytr, R. Groenwald; CONF-8310143-67, p. 22; NRC Water Reactor Safety Research Information Meeting, held 10/14/83 in Gaithersburg, MD.

5. "Development of Acoustic Leak Detection in a Primary Cooling System", K. Watanabe, T. Uchikawa, T. Kitihara, K. Shiba; CONF-8106200, Pt. 1; Second Annual International Conference of Canadian Nuclear Association and Canadian Nuclear Society, held 06/08/81 in 0ttawa, Canada; also published as report PNC-N-941-81-111.

6. "Leak Detection and Location in Light Water Reactors by Means of Acoustic Methods"; K. F. Fisher; CONF-8104162; Informal Meeting on Reactor Noise, held 04/28/81 in St. Englmar, Federal Republic of Germany.

7. "Experiences with 'On-Line' Diagnostic Instrumentation on Nuclear Power Plants"; R. Gopal, W. Ciaramitaro, J. R. Smith; CONF-8009305, pp. 209224, Conference on $0 n-L$ ine Surveillance and Monitorings of $P l a n t$ Reliability, held 09/23/80, London U.K. 
Acoustic Leak Detection (Continued)

8. "Acoustic Leak Detection Method in Piping System"; A. Kitajima, Karyoko Genshiryoku Hatsuden, V. 31, No. 5, pp. 527-534, May 1980 (In Japanese).

9. "Review of On-Line Leak Detection Methods for Reactor Systems"; G. J. Dan; CONF-7609173, pp. 67-73; Conference on Periodic Inspection of Pressurized Components, held 09/20/76 in London, U.K.

10. "High-Frequency Acoustic Leak Detection System Performance During Testing of the CRBRP Prototype Steam Generator"; R. L. Randall, Rockwell International; T. N. Claytor, Argonne National Laboratory; ESG-DOE-13430; Contract DE-AT03-83SF 11901; Issued 31 December 1984.

Detection of Oxygen Irradiation Products

1. "N13-Based Reactor Coolant Pressure Boundary Leakage System"; E. Dissing, L. Marbaech, S. Sande11, L. Svansson; Studsvik-NR-81-11, May 1980.

2. "Reactor Coolant Pressure Boundary Leakage Detection System"; E. Dissing, L. Svansson; Studsvik/K5-79-39, Page 54, August 1979.

3. "Procedure for Detecting Leakages of a Fluid Containing Radioactive Substances and Arrangement to Carry It Out"; J. Martucci, FRG Patent 2, $361,267 /$ A 07/04/74 (In German). 
In-service Inspection

1. Conference on Utility Experience in Reactor Noise Analysis; Charlotte, N.C., February 13-15, 1985.

2 Visit to Rockwell International Science Center, Dr. J. S. Schenwald.

3. "Development of Vibration Monitoring Systems for Light Water Nuclear Reactors Final Report," R. M. Kanazawa; NEDC-10780-5, Class 1, June 1977, Prepared by General Electric.

4. "Diagnostic Instrumentation Evaluation: 1983 Annual Report," Gordon D. Lassahn; EGG-PBS-6408, September 1983.

5. "Report on Diagnostic Instrumentation Evaluation," James R. Fincke, Gordon D. Lassahn; EGG-ID-6037; September 1982.

6. "Detection of Steam Generator Tube Leaks in Pressurized Water Reactors," William H. Roach; NUREG/CR-4032, EGG-2352; November 1984.

7. "Magnetomechanical Acoustic Emission of Ferromagnetic Materials at Low Magnetization Levels (Type 1 Behavior), "May Man Kwan, Kanji Ono, M. Shibata; Journal of Acoustic Emission, Volume 3, Number 3, 1984, pp. 144156.

8. "Pattern Recognition Analysis of Magnetomechanical Acoustic Emission Signals," Masayasu Ohtsu, Kanji Ono; Journal of Acoustic Emission, Volume 3, Number 2, 1984, pp. 69-80

9. "Magnetomechanical Acoustic Emission--A New Method for Non Destructive Stress Measurement," M. Shibata, K. Ono; 1 PC Business Press, 1981, 03089/26/81050227-08. 
In-service Inspection (Continued)

10. "A Portable, Real-Time, Holographic System for Imaging Flaws," B. P. Hildebrand, A. J. Doland, T. J. Davis, R. L. Silta; American Society for Metals, Metals/Materials Technology Series, 8310-009, 6th ASM International Conference on NDE in the Nuclear Industry, November-December 1983, Zurich, Switzerland.

11. "Laser Doppler Vibration Measurement Using Variable Frequency Shift," P. Buchhave, DISA Information, No. 18, September 1975, pp. 15-20.

12. "Measurement of Secondary Flows by a Frequency Tracking Laser Doppler Anemometer," Arnold Bertelsen; DISA Information, No. 27, January 1982, pp. 23-26. 
Temperature

T. V. Blalock, J. L. Horton, and R. L. Shepard, "Johnson noise power thermometer and its application in process temperature measurement," TEMPERATURE, $\underline{5}$, (2), 1249-59 (1982).

T. R. Billeter and C. P. Cannon, "Dual high temperature measurements using Johnson Noise Thermometry," ibid., 1245-48.

H. Brixy, R. Hecker, K. F. Rittinghaus, and H. Howener, "Application of Noise Thermometry in Industry under Plant conditons," ibid., 1225-37.

M. C. Decraton, "High Temperature Noise Thermometry for Industrial Applications," ibid., 1239-43.

R. L. Shepard, T. V. Blalock, D. C. Agouridia, J. L. Horton, "In Situ Calibration of Nuclear Plants Resistance Thermometers using "Johnson Noise Methods," EPRI HP-3113, Final Report Research RP 1440-1 (June 1983).

R. L. Shepard, T. V. Blalock, M. J. Roberts, "In Situ Calibration of Resistance Temperature Detectors in Nuclear Plants using Johnson Noise," Final Report EPRI Research Project RP 2254-1 (in preparation). 
Pressure

Literature related to pressure measurements are:

1. "Performance Assessment of Class IE Pressure Transmitters Subjected to Environmental Stresses," D. T. Furgal and C. M. Craft, SAND-84-1655C, CONF-8410142-31, p. 23, 1984.

2. "TMI-2 Pressure Transmitter Examination and Evaluation of CF-1-PT1, CF-2LT1, and CF-2-LT2," M. E. Yancey and R. C. Strahm, GEND-INF-029, Volume 2 p. 25,1984 .

3. "Moisture Permeation Into Nuclear Reactor Pressure Transmitters," M. R. Keenan, SAND-83-2165, p. 19, 1983.

4. "Data Integrity Review of Three Mile Island Unit 2," J. K. Jacoby et al., EG\&G (INEL), GEND-INF-023, Volume 3, p. 69, 1984.

5. "Instrumentation of an HTR and its Environmental Conditions," G. E. Kaiser, IAEA-TC-389/6-11, p. 5, 1983.

6. "Closeout of IE Bulletin 80-16: "Potential Misapplication of Rosemount Pressure Transmitters," R. S. Dean, W. J. Foley, A. Hennick, Parameter, Inc., NUREG/CR-3047, 1983.

7. "Field-Harden Instruments and Electrical Components for Nuclear Plant Applications - Project Planning," C. W. Mayo, et al., Science Application Inc., EPRI-NP-3649, Volumnes 1 and 2, 1984.

8. "LMFBR Program Plan - Element, Instrumentation and Control," WASH-1104, Second Edition, December 1972.

9. "Pressure Transducers for Nuclear Applications," E. G. King, MSA Research Corporation, March 1967 Proceedings of the Symposium on Liquid Metal Instrumentation and Control, ANL-7380, pp. 65-69. 
Pressure (Continued)

10. "A Miniaturized Pressure Sensor for LMFBR Environment," J. E. Kinzer, Atomics International, March 1967, Proceeding of Symposium on Liquid Metal Instrumentation and Control, ANL-7380, pp. 63-64.

11. "The Measurement of Free Fission Gas Pressure in Operating Reactor Fue 1 Elements," M. B. Reynolds, GEAP-4135 General Electric Atomic Power Equipment Department, January 23, 1963.

12. "High-Temperature Pressure Gage," E. C. King and V. K. Heckel, Mine Safety Appliance Company, Technical Report No. 45, File 1115, January 5, 1956.

13. "Design Parameters and Performance Characteristics of Miniature Pressure Transducer System Using a Fluid Filled Bellows Sensor," ANL-7574, October 1969.

14. "Development and Test of FFTF Prototype Fast Response Pressure Transducer," G. J. Twa, LMEC-TDR-744, February 1, 1974.

15. "Sodium Pressure Measurements," G. J. Twa and F. L. Fletcher, Japan/U.S. Seminar on Sodium Technology and Instrumentation and Contro1, June 12-16, 1978, Richland, Washington.

16. "Testing of the FFTF Plant Protection System Pressure Transducers." G. J. Twa, LMEC-17-5, G. J. Twa, January 15, 1978.

17. "Metallurgical Evaluation of FFTF PPS Pressure Transducer Interface Seal Assembly After Liquid Sodium Service," ETEC-78-11, September 30, 1978.

18. "Pressure Transducer Failures During Liquid Metal Service," E. G. Thompson and R. K. Wagner, ETEC-80-8, September 30, 1980.

19. "EBR-II Instrumentaion Experiences," K. J. Moriarty, Argonne National Laboratory, Proceedings of the Symposium on Liquid Metal Instrumentaion and Control, INEL, ANL-7380, pp. 23-28, March 1962. 
Pressure (Continued)

20. "Liquid Metal Pressure Measurement State-of-the-Art Study," H. W. Slocomb, LMEC-MEMO-68-7, 1968.

21. "Pressure Transducers for Treat Sodium Loops," L. E. Robinson and R. T. Purviance, ANL-7107, June 1969.

22. "Performance of Microwave Pressure/Temperature Sensor in Liquid Sodium," T. R. Billeter, HEDL, IEEE Transactions on Nuclear Science, Volume NS-21, October 1974.

23. "Progress Report February 1, 1969 - October 21, 1969," Liquid Metal Bearing Technology for Lease, High Temperature Sodium Rotating Machinery, Report No. NYO 3930-C, Mechanical Technology, Incorporated.

24. "Testing of Sodium Vapor Pressure Measuring System," G. J. Twa, K. S. Akamine, and W. T. Dand, ETEC-79-9, November 15, 1979.

25. "Sodium Pressure Measurement System Development Status Report," G. J. Twa, ETEC-84-17, 1984. 
Flow

1. Review group meeting on two-phase flow instrumentation, NUREG/CP-0006 March 13-14, 1978 at RPI, Troy, New York.

2. Review group conference on Advanced Instrumentation for Reactor Safety, NUREG/CP-0007, at U.S. Nuclear Regulatory Commission on July 24-26, 1979.

3. Review group conference on Advanced Instrumentation Research for Reactor Safety, NUREG/CP-0015 at ORNC, July 29-31, 1980.

4. Proceedings fo $1977,78,79,80,81,82$. Symposium on Instrumentation and Control for Fossil Energy Processes. The symposia were sponsored by DOE and ANL and were held in Chicago, Newport Beach, Denver, Virginia Beach, San Francisco and Houston.

5. Approximately 200 papers on flow measurements. 
Flow (Continued)

References specifically related to liquid metal flowmeters are:

1. "Liquid Metal Flow Measurement State-of-the-Art," G. E. Turner, LMECMEMO-9, 1968.

2. "Magnet Flowmeter Placement Test," H. W. Slocomb, LMEC-MEMO-31, 1968.

3. "Transit Time Flowmeter - 6-Inch Diameter Water and Sodium Testing Summary," R. De Muri, LMEC-72-4, 1972.

4. "Critique of Present and Possible Future Sodium Flow Measurement Techniques," G. Turner, LMEC-TDR-74-8, 1974.

5. "ALIP/F lowmeter Calibration Report," V. De Vita, ETEC-TDR-78-13, 1975.

6. "16-Inch Permanent Magnet Flowmeter Performance in Liquid Sodium - Final Report," V. De Vita, ETEC-79-14, 1979.

7. "16-Inch U1trasonic Flowmeter Performance in Liquid Sodium," V. De Vita, ETEC-81-17, 1982.

8. "16-Inch Electromagnetic Flowmeter Performance in Liquid Sodium," V. De Vita, ETEC-82-3, 1983.

9. "SPTL-2-ALIP and PM/FM Calibration, V. De Vita, ETEC-TDR-82-6, 1982.

10. "24-Inch Permanent Magnet Flowmeter Performance in Liquid Sodium," V. De Vita, ETEC-84-7, 1984.

11. "16-Inch and 30-Inch Bypass Flowmeter Performance in Liquid Sodium," v. De Vita, ETEC-84-11, 1984.

12. "Pulsed Neutron Activation (PNA) Tests in a 24-Inch Test Pipe," V. De Vita, ETEC-TDR-84-12, 1984. 
Level

Literature related to water reactor level measurement includes:

1. "Proceedings Conference on Reactor Vessel Liquid Level Measurement," NUREG/CP-0016, 1980.

2. "Analysis of the Performance of the Westinghouse Reactor Vessel Level Indicting System for Testing at Semiscale," J. E. Hardy and G. N. Miller, NUREG/CR-2770, 1982.

3. "Evaluation of Thermal Devices for Detecting In-Vessel Coolant Levels in PWR's," J. E. Hardy et. al., NUREG CR-2673, 1982.

4. "Proceedings Topical Meeting on Advances in Reactor Physics and Core Thermal Hydraulics," NUREG/CP-0034, 1982.

5. "Proceedings International Meeting on Thermal Reactor Safety," NUREG/ CR$0027,1982$.

6. "Evaluation of Instrumentation for Detection of Inadequate Core Cooling in Boiling Water Reactors," J. Lewin, NUREG/Cr-3852, 1984.

7. "Ultrasonic Level and Temperature Sensor for Power Reactor Applictions," W. B. Dress and G. N. Miller, NUREG/CR-3856, 1984.

8. "Implementation of TMI Action Plan II F.2 (NUREG-0737); Additional Instrumentation for Detection of Inadequate Core Cooling," NRC Staff Paper, SEC-82-407, 1982.

9. "LOFT Experimental Transducers for Mass Flow and Liquid Level Detection," L. D. Goodrich, CONF-8010103-3, 1980.

10. "Barium Silicate Glass/Inconel X-750 Interaction," P. V. Kelsey, Jr., W. T. Siegel, and D. V. Miller, CONF-800765-1, 1980. 
Level (Continued)

11. "Development of an Improved-Contact Liquid Level Probe for Pressurized Reactor Vesse 1s," P. V. Kelsey, Jr., EGG-FA-5487, 1982.

12. "A Review of Proposed Instrumentation for Measurement of Water Level as a Means of Detecting Inadequate Core Cooling in Pressurized Water Reactors," P. G. Bailey and M. Meri10, EPRI-NP-2727-SR, 1982.

13. "Alarming Device for the Lowering of Water Level in the Reactor Core," Toru Mitsuta, Takashi Kiguchi, and Takao Watanabe, Hitachi, Ltd., Japanese Patent 57-119, 295/A/, 1981.

14. "Reconstruction of Level Monitoring Gauges of LR-0 Reactor," E. Gluza, Nukleon (Czechoslovakia), No. 2, pp. 9-11, 1983.

15. "Meeting the Need for Unambiguous PWR Coolant Level Measurement," F. Reisch, Statens Kaernkraftinspection, Stockholm, Sweden; Nuclear Engineering International (England); V. 29., No. 350, pp. 34-38.

16. "Non-Invasive Water Level Measurements at LOFT Using a Neutron Detection System," A. Baratta, W. Jester, E. Okyere, M. Gundy, G. Ine1, M. Kibler, Penn State University, NUREG/CP-0048, Vol. 5, pp. 225-260.

17. "Monitoring Reactor Vessel Liquid Level with a Vertical String of SPNDS, "J. P. Adams and V. T. Berta, INEL, Transactions of the American Nuclear Society (U.S.), Vol. 45, pp. 870-872, 1983.

18. "Continuous Measurement of Coolant Liquid Level During the MT-4 Experimental in the NRU Reactor," R. K. Marsha11, C. L. Moh1, P. N. McDuffie and R. A. Scoggin, PNL, NUREG/CR-3183, 1983.

19. "Development of an In-Vessel Water Level Gauge for Light Water Power Reactors," K. Ara, N. Wakayama, and K. Kobayashi, JAERI, Proceedings of the International Meeting on Thermal Nuclear Reactor Safety, ANS, Chicago, IL, CONF-820802, Vol . 3, pp. 1667-1680. 
Level (Continued)

20. "Pressurizer Level Measurement Inside PWR Nuclear Plant Using Resistance Type Heat Sensors," Ahmed E1 Moussaoui, CEA-N-2288, 1982.

21. "Unique Concept for Liquid Level and Void Fraction Detection in Severe Fuel Damage Tests," R. D. Tokarz, S. L. Crowe11

22. "Water Level Measurement and Control in Large Boiling and Pressurized Water Reactors," C. Baker, Sensor and Systems Limited, Derby, England, ISA Power Instrumentation Symposium, Chicago, Illinois, CONF-8005167, pp. 85-93. 
Level (Continued)

Literature related to sodium level measurements include:

1. "Liquid Metal Level Measurement (Sodium) State-of-the-Art Study, "H. W. Slocomb, NAA-SR-MEMO-12582, Atomics International, November 15, 1967.

2. Mine Safety Appliances (MSA) Sodium Level Measuring Systems Performance Test Report, " J. A. Klea, ETEC-84-8, Energy Technology Engineering Center, May 15, 1984.

3. "Sodium Level Transducers Testing to $1050^{\circ} \mathrm{F}$," B. E. Fischer, LMEC-TDR74-2, Energy Technology Engineering Center, January 21, 1974.

4. "Testing of WETD Prototype Level Transducers," B. E. Fischer, LMEC-TDR75-3, Energy Technology Engineering Center, May 30, 1975.

5. "Annual Technical Progress Report, January-December 1975, "Liquid Metal Engineering Center (LMEC), LMEC-76-1, Liquid Metal Engineering Center, April 30, 1976.

6. "Calibration of the FFTF Level Measuring System," B. E. Fischer, LMEC77-3, Liquid Metal Engineering Center, December 1, 1977.

7. "Testing of the Kaman Prototype Level Transducer," B. E. Fischer, LMECTDR-75-13, Liquid Metal Engineering Center, December 19, 1975.

8. "Interatom Sodium Level Measuring System Performance Test," J. A. Klea, ETEC-80-7, Energy Technology Engineering Center, June 16, 1980.

9. "PNC Sodium Level Measuring System Performanc eTest," J. A. Klea, ETEC-81-10, Energy Technology Engineering Center, December 15, 1981.

10. "Sodium Level Measurment System Development Status Report," J. A. Klea, ETEC-84-16, Energy Technology Engineering Center, June 26, 1984. 
Coolant Chemistry

1. "Availability of Full Size Ceramic Electrolyte Tubes for Oxygen in Sodium Electrodes," J. J. McCown, HEDL, Letter 8151671, May 19, 1981.

2. "Hydrogen Injection Test Results," W. E. Burns, ETEC-TOR-83-II, 1983.

3. "Nuclear Power Reactor Instrumentation System Handbook," Joseph M. Marrer and James G. Beckerley, TID-25952-PI, 1973.

4. Monitoring Techniques for PH, Hydrogen, and Redox Potential in Nuclear Reactor Circuits," D. D. McDonald, et. al., EPRI-MP-2806, 1983.

5. "Feedwater Chemistry Requirements for HTGR Steam Generator Operation," W. G. Schuetzenduebel and J. J. Eisenhoter, General Atomics Company, ASME $76-W A / N E-1, p .1-11,1976$.

6. "State-of-the-Art Water Chemistry of Steam Generators with Emphasis on CRBR Specifications," J. L. Simpson et. al., GEFR-00463, 1979.

7. "Water Chemistry in the Dounreay Prototype Fast Reactor (PFR) Power Station," K. R. Melhuish and J. A. Bray, CONF-7710187--International Conference on Chemistry of Nuclear Reactor Systems, Bournemount, UK, October 24, 1977.

8. "Survey of Modern Boiler Water Practice: Boiler Water Control to Minimize Corrosion of the Steam Generators in the Clinch River Breeder Reactor Plant," D. Dutina, GEAP-14042, 1976.

9. "Improved Electrodes for BWR In-PIant ECP Monitoring," J. Leibovitz, et. al., EPRI-NP-2524, 1982. 
-

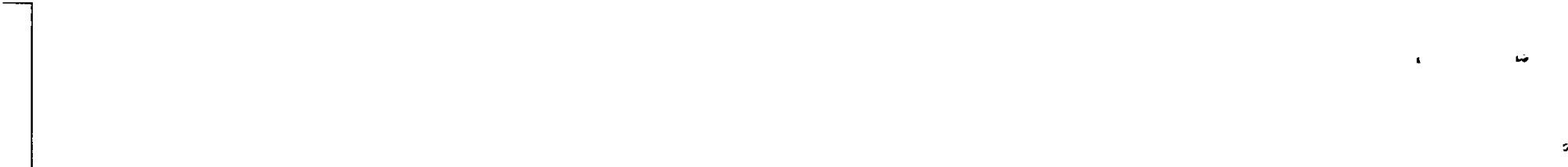




\section{APPENDIX A}

- Visit to University of Florida

o Visit to DuPont

- Visit to Purdue University

- Visit to University of Arizona

- Visit to Argonne National Laboratory

- Conference report "Optical Fiber Communication and Optical Fiber Sensors"

- Sensor Vendor Survey

- Professional Societies Related to Sensors 


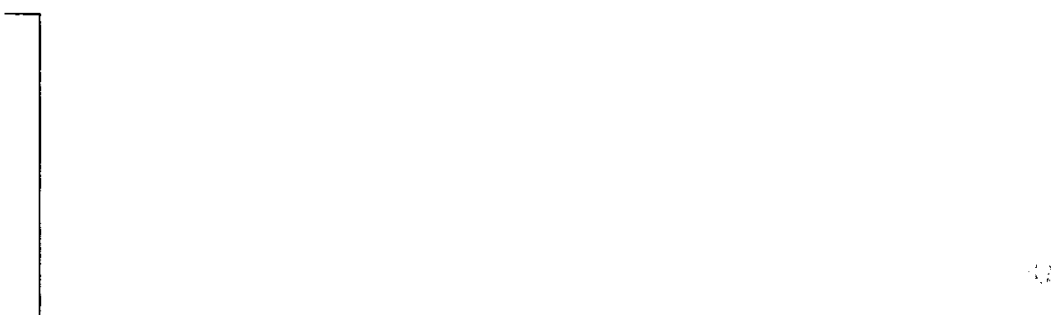




\section{TRIP REPORT \\ University of Florida \\ (Gainesville)}

February 6, 1985

Purpose of Visit To review sensor research at the University of Florida to determine what development needs were being addressed relative to the evaluation and assessment being performed by the DOE High Technology Initiative Task Team on Sensors.

Participants

Sensors Task Team:

Univ. of Florida:

Ed Carroll

(Prof. of Nuclear

Engineerng)

G. Bosman

(Dept. of Electrical

Engineering)
Dennis N. Elliott

(West inghouse)

Bob L. Sullivan

(Chairman \& Professor Department of Electrical Engineering)

Peyton Z. Peebles

(Professor of Electrical Engineering)

Keith L. Doty

(Professor of Electrical

Engineering \& Director of

Machine Intelligence Laboratory)

Bill Jones

(Visiting Professor from Texas A\&M)

Discussion

After a brief discussion of the goals of the DOE High Technology Initiative Task Team on Sensors individual professors described the research that they were leading at the University of Florida. Of particular interest was the research into a variety of sensors for robotic applications described by Dr. Doty. This included implementation of a novel scheme for object detection and identification. The idea is to use a "silhouette" detector as the robot base. An array of photo detectors scan a glass surface and detect gradients in light intensity. The information so obtained is analyzed by a microcomputer and a pattern of the "base" of the object is formed. Other recent robotic sensor research efforts have included: 
- Robot obstacle detection and avoidance determined by actuator torques and joint positions.

- A microcomputer controlled acoustic proximity detector.

- Proportional sense of touch in robots

- Compound eye vision systems for robots.

Sensors for robots and the associated signal processing receives a great deal of attention because of the extensive research in robotics at the University of Florida. A tour of some of the robotic projects was arranged and included demonstration of tactile sensing as well as surface roughness discrimination.

Another topic of special interest was the fiber optics research being performed and a laboratory tour was given to demonstrate some of the research underway. NASA Kennedy Space Center has entered into an arrangement with the University of Florida to investigate the many methods that are and have been used in flow metering and liquid level detection. As a result of this investigation research is being performed on the use of a laser beam directed into an optical fiber mounted across a flow field. The characteristics of the beam emerging from the optical fiber are analyzed as to any changes in flow velocity and/or mass flow rate using a spectrum analyzer. For liquid level measurement gamma ray probe devices have been chosen as the most promising for further development. Very weak gamma sources were chosen for experimental work using glass and plexiglass vessels filled with water and water-and-air mixtures. The gamma source is attached to a float on the surface of the liquid and its position is monitored by detectors on the outside of the vessels.

Other university research topics of discussion were:

- Silcon carbide temperature detectors for applicaton in jet engine instrumentation for temperatures up to $2000 \mathrm{C}$.

- Radiation flux monitoring. 


\title{
DEVELOPMENTS IN ADVANCED SENSORS
}

\author{
Visit to \\ E. I. DuPont De Nemours and Company, Incorporated \\ February 18, 1985
}

\author{
R. Vittal Rebbapragada \\ Burns and Roe, Incorporated \\ 800 Kinderkamack Road \\ Oradel1, New Jersey 07649 \\ (201) 265-2000, Ext. 2016
}


Purpose:

To assess work done by Dupont in the area of advanced sensors for technology transfer to the nuclear power industry.

Date:

February 18, 1985

Place:

E. I. DuPont DeNemours and Company

Engineering Department

Louviers Building

Newark, Delaware 19898

Persons Attended:

Dupont

Donald R. Dodd

Charles B. Moore

Cullen G. Langford

James B. Arant

Victor J. Maggioli
Burns and Roe

H. Cody

R. V. Rebbapragada
Argonne National Laboratory

Paul Raptis

\section{Discussion:}

1. DuPont utilizes commercially available equipment in their plants. The technology developed in their laboratories is turned over to sensor developers prior to its implementation in their plants. They recommend having a test bed installation and obtaining results prior to its implementation in commercial plants. 
2. DuPont has done extensive development work in the following areas:

- Process analysis

- Vortex shedding devices using fibre optics

- Infrared non-intrusive type temperature detectors for location in hazardous type process application

- Leak detection for underground emission of hydrocarbons

3. In the area of temperature measurement, DuPont traditionaliy uses RTDS. They are getting smaller and their response is as good as thermocouples. Dupont is familiar with the development of tube-skin thermocouples: They make a connection to the metal surface that is much easier and recommend pursuit of this technology for application to the Nuclear Power Generating Stations (NPGS).

4. There are numerous developments in the area of pressure transmitters:
- Small economical transmitters
- Far more accurate devices

They forecast that sensors will transmit digital signals even before the end of the decade. Power supplies will be located in the transmitters, using devices such as solar cells and batteries. Electronics used in the sensors have developed to such an extent their power requirements have come down, and the future designs may have power transmitted through fibres, (instead of power packs located in Instrument Racks) with power distribution at field boxes to the valves.

- Distributed control design of Dupont uses the following features:

-- Sensors and transmitters having adequate voltage surge rating

-- Not susceptable to RF fields 
5. DuPont is impressed with the turbine meter for flow measurement developed by Quantum Technology Corporation using optical techniques. It has an accuracy of about $0.1 \%$. Quantum Technology also makes a low frequency, long wave acoustic meter for flow measurement and should be investigated by NPGS.

6. Dupont developed a fail-safe ultra reliable alarm relay, marketed by Rochester Instruments that has application to NPGS.

7. For level measurement, especially using capacitance and RF techniques DuPont recommended DREXEL BROOK. They have satisfactory experience in the area capacitance techniques and are reliable.

8. Dupont recommends redundancy in levels measurement. They recommend alarm from a different switch for e.g. high level alarm and high level indication.

9. Dupont has developed a rotary valve actuator for fire resistance, which incidentally has also high radiation resistance and is applicable to NPGS. They recommended to contact Randon Research, Houston.

10. They recommended a contact: Or. Frederick Liu, Eastern Machinery, Landenburg, Pennsylvania who has a very promising development in the area of vortex meters, which they believe is the flow meter of the future.

11. DuPont recommended a contact with KURZ Instrument, that developed a thermal meter for multiphase flows using ultrasonic technology.

12. For verification of sensor-set points and calibrations, DuPont adopts the following on-line approach:

- Develop histogram

- Use a pilot signal, and integrated using microprocessor

- Use 2 out of 3 voting techniques. 
(They believe sensors of the future will have built in 2 out of 3 polling.)

13. DuPont recommends the following in the area of direct digital control:

- System will be designed to General Motors Manufacturing Automation Protocol (MAP).

- Use ring address system minimizing the cost of wiring.

- No standard exists at the sensor level of communication interface. PROWAY will be an ISA standard, and Appendix B to IEEE 802.4 but doesn't address sensor interface.

- Believe ADA language will not be suitable for application at the sensor to local area network interfaces and should not be used at the sensor level.

14. DuPont has done the following in the area of analysis instruments:

- Plasma chromotograph to determine concentration in parts per billion (PPB) of toxic chemicals

- Calorimetric instruments using infrared and uitra-violet absorbents.

- Surface coatings using infrared techniques by studying its spectral emissivity.

o Wrapping a fibre in a FTR prism, study the change in the electric characteristics of the material in an electrical field.

- Power acoustics for ultrasonic welding.

- X-ray techniques did not help much in material inspection.

o on-line instrument to determine the addition in a process. 
15. DuPont is using a gamma monitor specially developed by Los Alamos for inventory control of special nuclear materials. This has used Sodium Iodine/Germanium Crystals

16. Dupont has experienced the following in the application of valves:

- Quality of control valves is poor.

o Quality of fittings is very poor.

Recommend for NPGS, use of piston actuators and do away with the spring and diaphragm actuator which pose additional burden on seismic qualification.

17. For sensor tubing, DuPont only uses stainless steel and recommends the same for NPGS. They recommended $1 / 2 "$ as a minimum on compressible fluids and $3 / 8$ " or 1/2" for other impulse 1 ines, $1 / 2$ minimum for gauges. DOE should promote a standard for NPGS and industry wide application.

18. Dupont recommends in conclusion that multiple instruments and taps should be considered for defense in depth and establish confidence to the operations for instrument accuracy.

19. Valve position indication is a problem and DuPont's recommendation is:

- Instead of limit switches use proximity switches.

- Fibre optic switches are becoming available.

- LVDT for intermediate positions.

Lastly before non-intrusive technology is used, DuPont recommends test installations in operating plants and with proper real-time application in the field extend the new technology to the future generation plants. 


\section{DEVELOPMENTS IN ADVANCED SENSORS}

$$
\text { visit to }
$$

Purdue University

Mechanical Engineering Department

$$
\text { February 5, } 1985
$$

R. Vittar Rebbapragada

Burns and Roe, Incorporated

800 Kinderkamack Road Oradel1, New Jersey 07649 (201) 265-2000, Ext. 2016 
Purdue Laboratory

for

Applied Industrial Control

I met Dr. T. J. Williams, Director of Purdue Laboratory for Applied Industrial Control (PLAIC) on February 5, 1985. His extensive consulting services have included work for the U.S. Department of Energy. While he was never associated with the Nuclear Power Generating aspects of the Applied Industrial Control, he is considered as one among the leaders in the forefront of Industrial Control. At the time of my visit Dr. Williams was actively involved as a member of the Automation and Robotics Panel preparing an economic evaluation study for the U.S. Congress for a permanent station in space. A copy of his earlier work, Advanced Automation and Robotic Technology for a Manned Space Station was handed over to E. Purvis of the U.S. DOE on February 8, 1985. In addition, the following technical reports relevant to the advanced sensor task force were given to me by $\mathrm{Dr}$. Williams and are available to task force members for review.

1. PLAIC Report Number 77, The International Purdue Workshop on Industrial Computer Systems and its Work in Promoting Computer Control Guidelines and Standards.

2. PLAIC Report Number 98, Tasks and Functional Specifications of the Steel Plant Hierarchial Control System, Volumes I and II.

3. PLAIC Report Number 111 (DRAFT), Hierarchial Computer Control in the Pulp and Paper Industry.

4. Publication of the International Purdue Workshop on Industrial Computer Systems.

5. Description of the International Purdue Workshop on Industrial Computer Systems. 
Dr. Williams briefly explained the role of Artificial Intelligence (AI) and its interface with Automatic Control Systems at the Level 1 control, where they interface with field sensors.

The figure on the next page illustrates the principles of a hierarchical digital control system which is applicable to Nuclear Power Generating Stations. Development of advanced sensors with direct digital interface require network interface at level 1 and Level 2.

Artificial Intelligence and its interface with the Level 1 and 2 controls will come about as illustrated in the following Figure: 


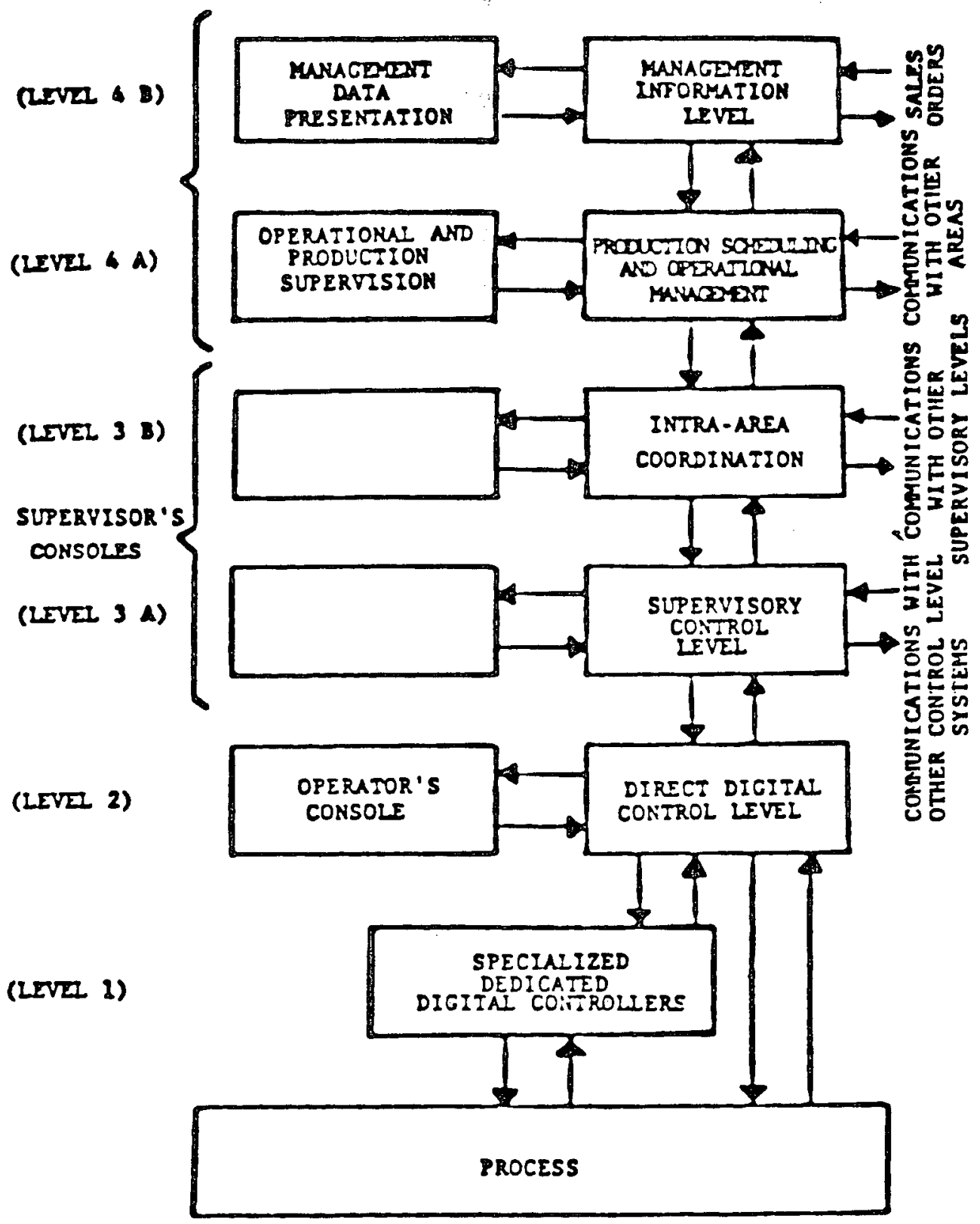

Distributed Computer System for the Overall Steel Mill Hierarchy Computer Control Structure 
Dr. Williams mentioned that, as yet, there are no universally accepted standards for an in-plant transmission medium. This medium would be used for connecting the computer nodes of the required network to each other, to the plant manufacturing system itself and its operating personnel. The current work by the IEEE Committee on Local Area Networks is an important factor and can form the basis for the required standards if desired by the users.

GM's Manufacturing Automation Protocol (MAP) specifications will permit several different computers and programmable controllers to communicate. GM's MAP Involvement results from a special interest in accelerating the development of a standard for broadband buses. The company is working with the IEEE 802 committee, ANSI, ECMA and the ISO.

Process Data Highway (PROWAY) developed by Purdue can use coaxial or fibre optic bus with the following capabilities:

-- 1 Megabit/Sec rate for data transfer

- 5 kilometers total transmission distance

-- Undetectable error rate of $1 \times 10^{-15}$

Presently microcomputer chips utilized in the MAP development are designed to the IEEE 802.4 specifications.

PLAIC has done considerable work on industrial computer system and developed extensive standards and the following summarizes its background:

The International Purdue Workshop on Industrial Computer Systems, in its present format, came about as the result of a merger in 1973 of the Instrument Society of America's (ISA) Computer Control Workshop with the former Purdue Workshop on the Standarization of Industrial Computer Languages, also cosponsored by the ISA. This merger brought together the former workshops' separate emphases on hardware and software into a stronger emphasis on engineering methods for computer projects. Applications interest remains in the use of digital computers to aid in the operation of industrial processes of all 'types. 
$1.0 \quad$ Introduction

During the visit on February 5, 1985, the briefing on sensor developments was given to Drs. Raymond Viskanta and David. Many of these techniques are applicable to nuclear power plants.

\subsection{Facilities Visited}

- Fluid Mechanics Laboratory

-- Laser Doppler Anemometer

- Heat Transfer Laboratory

-- Shadography

-- Magnetic Interferometry

-- Temperature Distribution in Combustion System for National Bureau of Standards

- Flow Measurement Laboratory

-- Flow Meter and Sensing Temperature impose a heat flux and measure the temperature

- Optical Measurement Laboratory

-- Flow (visualization in lab environment)

-- Interferometry, quantitative temperature

-- Shadowgraph for flow visualization

-- Spectral Remote Sensing in Semi Transparent Solids--Optical Programs--Surface Temperature 
2.0 Sensor Technology

2.1 Measurement of Temperature in High Temperature Furnaces and Processes

Purdue University is engaged in research associated with advanced sensors in the following areas:

- Improved temperature-measuring methods using radiation thermometry and thermocouple technology for temperatures in the range of about $500^{\circ} \mathrm{C}$ to $2200^{\circ} \mathrm{C}$. Radiation thermometry will use visible and infrared spectral, spot and scanning types. Work done involved surface temperature measurement in furnances, methods of measuring gas temperatures important for characterizing furnance conditions, problems encountered in performing field measurements, especially those due to radiation from luminous flames and furnace walls.

The measurement equation used is based on inferring temperature from radiation thermometry observtions. The radiation thermometer is considered to be a radiometer calibrated to correctly indicate the temperature of a black boy target. Some of the aspects to be evaluated include:

- Target emissivity

- Reflected Irradiation

- Line-of-Sight atmospheric gas absorption

- Sensitivity of the above effects on wave length.

Purdue University (Dr. DeWitt) recommended to contact the Society of Photo-Optical Instrumentation Engineers (SPIE), which holds frequent symposiums on thermal infrared sensing for diagnostics and control.

Society of Photo-Optical Instrumentation Engineers (SPIE)

Post Office Box 10

Bellingham, Washington 98227 
Purdue is conducting research in seeking new methods for measuring optical properties of semitransparent materials at high temperatures. The analysis of radiative heat transfer from high temperature opaque materials requires knowledge of the surface radiation properties emissitivity, absorptance or reflectance. It is important therefore that determination of optical properties such as refractive index and extinction coefficient of non-scattering semitemperature material be made. Fused quartz and sapphire were used with accuracies of $+10 \%$.

\subsubsection{Problems With Thermocouples and New Thermocouple Developments}

Problems with Thermocouples

The two standard types of temperature measurement systems in process control are probes (primarily thermocouples) and radiation thermometry. Thermocouples distort the temperature field by conduction and respond to radiation from other than local sources. Unless great care is exercised in the location and use of contact thermocouples, large temperature errors may result. Thermocouples require recalibration, and their readings vary with surface height for internal temperature measurement. An additional problem with immersed thermocouples is their effect on the process at time producing cooling or contamination. In the formation of flat glass, TV panels, and containers, and in operation such as annealing and tempering the $u e$ of thermocouples is impractical. This is due to interference with process operations, poor thermal contact with the surface of the glass, or slow response. In order to overcome the difficulties associated with the use of contact thermocouples, radiation pyrometers may be used for surface temperature measurements.

Developments in the Area of Thermocouples

- Tube skin thermocouples for higher temperatures. Survival of these thermocouples at higher temperatures may be a problem. Developments addressed include NiSil-NiCrosil assemblies. As to the accuracy, 
the indicated readings are 30 to $150^{\circ} \mathrm{C}$ higher than the actual temperatures and must be connected, work is in progress to further develop this technology.

\subsection{Radiation Thermometry}

Methods of temperature measurement using radiation thermometers (optical and infrared pyrometers) are becoming more attractive for industrial applications. In addition to the non-contact advantage, the methods can be realized by a wide selection of thermometer types with features suited for control of processes. With the growing use of computers for control purposes and the increased opportunity for improving process productivity, it has become essential to better understand the performance of radiation thermometers in the industrial environments where they are applied.

Infrared thermometry and spectral remote sensing represent attractive techniques for the following reasons: 1) The measurement temperature technique is nonintrusive since probes are not introduced. 2) Distortion of the measured field by the sensor is absent, 3 ) the medium is not exposed to a field of external electromagnetic radiation, i.e., measurement is passive type, and 4) Measurements can be made from a single remote location providing the presence of intervening media, if any, is correctly taken into account.

A radiation thermometer (RT) is a radiometer calibrated to correctly indicate the temperature of a blackbody. The radiometer, whether it be of the spot-type or a line or area scanner, senses radiant flux from the target and provides a signal output which, through a calibration algorithm, is used to provide a measure of the target temperature. In most industrial applications, one generally finds non-black targets in the presence of hotter surroundings with gaseous atmospheres that absorb, emit, and/or scatter radiant flux. The procedures for inferring the target temperature for these situations can be extremely difficult and the accuracy of the measurement can be poor. Referred to 
as the measurement problem, this is the major difficulty facing most users. Also of importance to the well-informed user are the procedures used to calibrate radiation thermometers.

Developments in the field of radiation thermometry, including applications, can be traced through the publication, Temperature, Its Measurement and Control in Science and Industry. In the 1972 publication, Warnke provided an extensive oveview of the types of thermometers with descriptions of construction features, optical systems and detector types. Since that time, the silicon photodetector technology has improved dramatically to provide light-weight reliable thermometers for the 0.5 to 1.1 (micron) spectral range. Improvements in infrared detector technology have also fostered the availability of low-cost thermometers in the infrared region. Unfortunately no extensive, updated survey of instrument status has been published to provide guidance to potential users for thermometer selection. The dilemma becomes more evident with the awareness that there exists nearly 300 models of radiation thermometers offered by more than 25 instrument manuf acturers.

\subsection{Calibration Services in Radiation Thermometry}

There are are at least three reasons why the RT user should have some background on the principles of calibration. First, the user needs to properly interpret the instrument specificationf for accuracy of temperature measurement. Against what traceable temperature standard has the instrument been calibrated? Second, the user may need to establish in-house capability to check (or reproduce) instrument calibration; this is especially desirable if the instrument is subjected to frequent use in the industrial environment. The third, and perhaps the most important reason, is to understand the procedure used for calibration will place any limitations on use of the instrument. For example, the RT response may be different when viewing the same-sized target on sources of different size; this is preferred to as the size-of-source 
effect. From a more practical perspective, the major pitfall in a new application is not recognizing whether the conditions of the measurement are the same as that for which the calibration is valid.

A variety of calibration services is being offered by the Metrology Research and Development Laboratory (MRDL) in the Instrumentation and Controls (I\&C) Division of Oak Ridge National Laboratory (ORNL), from "standard" calibrations to what are essentially one time experiments in metrology for the special requirements that frequently arise in a multi-disciplinary research laboratory. Traceability is provided from 800 to $2300^{\circ} \mathrm{C}$ through NBS calibrated tungsten strip lamps, both vacuum and gas filled. The routine calibrations are extensively automated and all pyrometers are given an as received spot calibration before cleaning and adjusting. Archival records are maintained for each instrument calibrated in MRDL as a part of the I\&C Division's Maintenance Information System. The calibration equipment is described, a sample calibration procedure is examined in detail with typical data, and the records and recall systems are described. Special services, such as the calibration of windows are also described.

The demand on National Laboratories for calibration certificates for radiation thermometers has not been sufficient in the past to justify the development of a range of equipment and methods. On the other hand, radiation thermometers operating at 0.66 (micron), which have formed the basis for interpolation and extrapolation of the International Practical Temperature Scale above the Gold Point $\left(1064.43^{\circ} \mathrm{C}\right)$, have been the subject of large scale studies. This has led to an imbalance in facilities as far as the industrial user is concerned. In the past few years; however, industrial pressures, plus the desire to study the radiation scale of temperatures below the Gold Point, has led to some significant improvements in traceable accuracy.

Both calibration sources and thermometers are not available in the temperature range $0-1100^{\circ} \mathrm{C}\left(0-1000^{\circ} \mathrm{F}\right)$ with about one-tenth degree reproducibility. In adddition, sources and thermometers are available 
for use above $2500^{\circ} \mathrm{C}\left(4000^{\circ} \mathrm{F}\right)$. However, it is more difficult to achieve a traceability of $\pm 5^{\circ} \mathrm{C}$ with these devices and methods.

A recent important development has been the production in Japan of simple and inexpensive fixed-point blackbody furnaces. The furnaces give highly reproducible thermal arrests (freezing plateaus), and their uncertainty is limited mainly by the uncertainty of the emissitivity of their cavity. A value of $0.9995+.0005$ is claimed. This will result in a temperature uncertainty of between \pm 0.02 and $\pm 0.50 \mathrm{~K}$ depending on the temperature and the thermometer type. Results are also given on the use of a narrow angle thermometer than can be calibrated at four fixed points and then used with an algorithm to interpolate between the fixed points to a high degree of accuracy. This thermometer can, therefore, be used to transfer the calibration to larger blackbody sources suitable for routine calibration use.

Further Developments Needed in Radiation Thermometry

The noncontact characteristic of radiation thermometry, introduce other complications. The physical laws that govern the emission of thermal radiation are not always in concert with the basic principles underlying the operation of the instrument. This is true for example of partially transparent materials such as glasses. Any attempt to apply radiation thermometry to measure the temperature of glass is complicated by the fact that the energy received by the thermometer sensor arises not only from the surface, but also from the interior of the glass which may be at a different temperature than the surface. The sensor signal depends not only on the radiance of the target after it has been attenuated by the transmission of the environment and of the optical system but is also modified by the responsitivity of the detector. For the purposes of the present discussion it is sufficient to note that, in general, radiation thermometry requires more knowledge on the part of the designer and user than do methods of contact thermometry. 
Developments in Radiation Thermometry

Nuclear Industry

- EG\&G has developed an imaging optical pyrometer system for the 2000 to $3200^{\circ} \mathrm{k}$ temperature range. The design includes an imaging optical probe to gain access to fuel rods in an experimental nuclear reactor. Gas cooling and purging protect the probe from steam and aerosols at $2500^{\circ} \mathrm{K}$ temperature and $15.5 \mathrm{MPa}$ pressure. A remote controlled calibrated video sensor system operates with image processing and video recording equipment.

Petrochemical Industry

- Petrochemical industry has been extensively using radiation thermometry in the following context:

-- Accurate measurement of furnace tube wall temperature in a major ethylene plant (Dupont).

-- Infrared Scanning System to measure temperatures within the fire boxes of high temperature equipment in refineries and petrochemical plants. (Infrared Scanning Services, Houston, Texas).

-- Thermovision techniques are used to measure and control temperatures of the solid catalyst used for oxidation processes.

National Bureau of Standards

A new type of temperature measuring device is being developed at NBS. The optical fiber thermometer is a contact sensor in which a thin film cup assumes the temperature of a fluid stream or contacted solid and emits blackbody radiation. The radiation is then conducted through a sapphire rod typically $1 \mathrm{~mm}$ in diameter and on to a photon detector. Research at NBS has focused on proving the feasibility of the system, developing calibration techniques, defining the precision and dynamic 
response, and optimizing the materials systems of the probe. Applications under study include precision thermometry, measurement of gas and flame temperatures, molten metal thermal measurements, and turbine engine temperature profiling.

Currentiy, several temperature measurement techniques are being developed in the Center for Chemical Engineering at NBS. A fiber optic thermometer is being developed for gas temperature measurements in flames. A fiber optic probe is also being used for coal particle measurements in fluidized bed combustors. A technique, based on $\mathrm{OH}, \mathrm{CH}$ and $C_{2}$ emissions, is being developed for temperature measurements and combustion control in boilers, furnaces and gasifiers. A new technique, based on laser induced fluorescence, is being utilized for temperature measurements in flames. Finally, a novel technique, laser tomography, is being developed for measurements over a two-dimensional region. A detailed description of these techniques will be provided, and advantages and limitations of each will be discussed. 


\author{
VISIT TO \\ UNIVERSITY OF ARIZONA
}

February 12, 1985

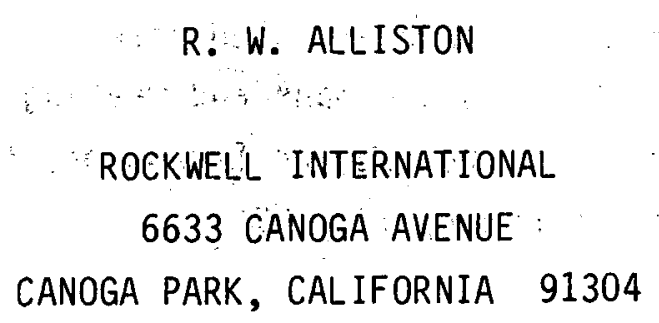


TRIP REPORT

UNIVERSITY OF ARIZONA

February 12, 1985

\section{INTRODUCTION}

On February 4, 1985, Dr. Roy Mattson (Department Head, Electrical and Computer Engineering) was contacted and the existence and objectives of the DOE Sensor Technology Task Team was explained to him. Or. Mattson indicated that the University of Arizona was performing sensor-related research in the following areas:

- Microelectronics which are capable of working at temperatures up to $600^{\circ} \mathrm{C}$ $\left(1112^{\circ} \mathrm{F}\right)$, high radiation and EMP environments

- Magnetometer for $200^{\circ} \mathrm{C}--300^{\circ} \mathrm{C}$ environment

- High Temperature $\left(250^{\circ} \mathrm{C}\right)$ CMOS

- Ion sensitive MOS FET (medical applications)

- Pressure sensors for measuring small changes in gas pressure (equivalent to a few feet of altitude; work being performed for air research)

- Photo-detector, IR range for astronomy applications (lunar and planetary)

After discussing the areas of sensor-related research, it was concluded that a visit to the University of Arizona campus and meeting with Dr. Mattson and his staff could be of a benefit to the Sensor Technology Task Team; therefore, a meeting was scheduled for February 12, 1985.

Upon arrival at the university campus, it was learned that Dr. Roy Mattson was ill and would not be able to attend the meeting; also, Dr. Robin Strickland 
111 and would not be able to attend as planned. However, other faculty were able to attend; the following staff members were in attendance:

Persons Visited: Dr. James N. Fordemwalt

$$
\begin{aligned}
& \text { Dr. William J. Kerwin } \\
& \text { Mr. Leonard Raymond } \\
& \text { Dr. John A. Reagan } \\
& \text { Dr. Robert Schowengerdt }
\end{aligned}
$$

\section{DISCUSSION}

Dr. Fordemwalt and Dr. Kerwin described the research that they were conducting on the development of integrated thermionic circuits (ITC) for high-temperature applications $\left(500^{\circ} \mathrm{C}\right)$. The basic approach taken has been to use the intrinsically high temperature phenomenon of thermionic emission in conjunction with thin film integrated circuit technology to produce microminiature vacuum triodes for ITC active devices. In laboratory tests, this technology (ITC) has demonstrated capability of withstanding $500^{\circ} \mathrm{C}$ for thousands of hours and radiation hardness to $10^{17}$ neutrons $/ \mathrm{cm}^{2}$ and $2.5 \times 10^{8} \mathrm{rad}$. Dr. Kerwin provided a copy of reference (1) which describes the development of the ITC active devices. A tour of the laboratory facility utilized for the ITC development was also provided by Dr. Kerwin. The ITC devices could have applications for sensors used inside containment of nuclear power generating stations.

Mr. Raymond described the research work that he is conducting on development of optical monitoring and three dimensional image enhancement which utilizes a light reflection technique, even with poor lighting. A tour of the laboratory facilities and a demonstration was provided by Mr. Raymond. This development could have applications in nucleàr power generating stations for remote viewing (i.e., surface cracks or defects inside a vessel, or equipment/material condition inside containment where there is poor lighting available). 
Dr. Reagan provided a description of the research work that he has been conducting in the field of remote sensing. The areas of his special expertise area:

- Electromagnetic Remote Sensing and Propagation

- Atmospheric Radiation and Optics

- Electro-Optical Instrumentation

- Solar Energy and Energy Management Applications in Buildings

- Semiconductor Device Design and Analysis

Dr. Reagan's areas of expertise and experience indicates that he is well qualified for research studies into applications of remote sensing utilizing electromagentic or electro-optical techniques; these could be aplied to nuclear generating stations. Or. Reagan supplied a resume (Attachment 1) and copies of references (2) through 11.)

Dr. Schowengerdt described the research work that the University of Arizona is performing in the area of image processing, analysis and pattern recognition of remote sensor imagery. He has been extensively involved in research work involving both hardware and software for several projects which utilized remote sensing and digital processing techniques (for control as well as monitoring). Dr. Schowengerdt provided a copy of his resume which lists the major tasks that he has performed and extensive list of publications. 
Visit to

Argonne National Laboratory

February 4, 1985

R. Vittal Rebbapragada

Burns and Roe, Incorporated

800 Kinderkamack Road

Orade11, New Jersey 07649

(201) 265-2000, Ext. 2016 


\title{
TRIP REPORT
}

Argonne National Laboratory (ANL)

(February 4, 1985)

\section{Persons Visited:}

\author{
Dr. Thomas P. Mulcahey \\ Dr. Shuh-Haw Sheen \\ Dr. Richard A. Valentin \\ Dr. A. C. Raptis \\ Or. A. DeVolpi \\ Dr. David S. Kupperman \\ $\mathrm{Mr}$. Robert S. Zeno \\ Dr. Roy Bennett \\ Dr. N. Gopalsami
}

ANL's Involvement Sensor Development

The Instrumentation and Control section of the Components Technology Division of ANSL is a multidisciplinary group carrying programs including water-reactor safety instruments, coal-process conversion, liquid-metal fast-breeder-reactor (LMFBR) instrument development, and plant and component dynamic-model simulation. High-temperature sensors using nuclear, electrical, electromagnetic, chemical, and acoustic techniques are being developed to measure flow, pressure, strain, conductivity, density, level, and steam-generator sodium-water leaks in the LMFBR. Fission counters, compensated ionization chambers, selfpowered and miniature in-core sensors, and the electronic instruments for nuclear-reactor neutron-flux monitoring systems are being experimentally evaluated. Dynamic modeling for simulation of components and systems includes pumps, heat exchangers, piping, turbine generators, and other major sytem hardware. A coordinated program library of component simulation models is being created, and a standardized language is being developed. Analytical models that describe the acoustic transmission function of complex internal structures such as LMFBR steam generators are being developed for acoustic- 
surveillance and leak-detection applications. Acoustic-transmission experiments are being performed, and the data obtained are being reduced using real-time spectrum analyzers and digital computers. Mini and microcomputer data-acquisition and signal-processing systems are developed to aid the experimental programs.

\section{Acoustic Instrumentation}

In the ANL instrument development program the main emphasis has been on development of instruments to measure mass flow rates and to perform on-line analys is of process flow streams. The flow instruments under development are based on acoustic/ultrasonic, electromagnetic, optical, or nuclear techniques, and the program has focused on development of nonintrusive instruments. For streams that are very abrasive and corrosive in nature, and at pressures as high as $4500 \mathrm{psi}$ and temperatures up to $2000^{\circ} \mathrm{F}$ or higher, nonintrusive instruments would be considered superior to intrusive instruments.

\section{Acoustic Doppler Flowmeter}

The classic Doppler effect is the shift produced by the relative motion between transmitter and receiver. In Doppler flowmeters the transmitting and receiving transducers are fixed with respect to each other, and the relative motion is produced by the particles or bubbles carried in the stream. The particles act as intermediate receivers and retransmitters. Commercially available acoustic Doppler flowmeters can operate in a temperature environment up to about $300^{\circ} \mathrm{F}\left(150^{\circ} \mathrm{C}\right)$, which is far below the requirements for powerplants. The temperature restriction on these Doppler flowmeters is mainly due to the temperature capabilities of the commercially available transducers. Another reason for the erratic behavior of the commercially available acoustic Doppler flow meters is the electronic circuits used to process the Dopplershift signals. In accordance with theoretical predictions, the output Doppler-shift.signal has single-tone characteristics and can be counted using the zero-crossing method. This type of procedure assumes turbulent-flow characteristic. In powerplant streams, however, at high temperatures, low velocities and high viscosities, the flow characteristics of the streams are laminar and the Doppler signal spectrum is not like a tone spectrum, but is distributed over a wide range of frequencies. 
To overcome these two problems, the Argonne National Laboratory (ANL) has developed a high-temperature acoustic Doppler flowmeter with the following characteristics:

- Measures the Doppler shift of backscattered ultrasonic waves from suspended particles

- Uses direct clamp on arrangement

- Detects flow profile and calculates average velocity

- Except for particles below 20 micron, it works well

- Needs calibration

- Waveguides or standoffs are used to transmit the sound through the temperature gradient

- An electronic circuit determines the corner frequency of the Doppler signal spectrum. Both of these characteristics are unique to the ANL system and have resulted in a high-temperature acoustic Doppler flowmeter that operated successfully in the recycle lines of the SRC-I, SRC-II and H-coal pilot plants

\section{BI-Gas Flow/No-Flow Indicator}

The BI-Gas process is being developed under a DOE contract by Bituminous Coal Research, Inc. at its pilot plant in Homer City, Pennsylvania. This process involves two-stage high-pressure coal gasification in an entrained-bed type reactor.

An indicator which could reliably monitor char flow under operating conditions is urgently needed. The primary goal is to distinguish between flow and noflow of the char for safety reasons; actual measurement of mass flow rate for process control would be a secondary benefit. ANL has designed, built, installed and successfully tested a flow/no-flow indicator in one of the char 
lines of the BI-Gas Pilot Plant. Char flow was monitored by a single passive acoustic microphone in the horizontal section of the char feed line. The char particles produced an acoustic signal whose amplitude and frequency spectrum depended on the flow velocity and concentration of the char.

The microphone is a rugged high-temperature unit developed at ANL-CT. It features two lithium niobate crystals in a symmetric drive configuration which makes the microphone sensitive to changes in pressure at the face, but relatively insensitive to acceleration forces transmitted by the support structures.

Acoustic Cross-Correlation Techniques

Currently ANL is working on developing the active acoustic cross-correlation technique for solid/liquid and solid/gas mass flow measurements, the acoustic time domain reflector meter for temperature measurements and has also determined the feasibility of level measurements by acoustics. In the active acoustic cross-correlation flowmeter acoustic energy is transmitted by a transducer into the media, the media in turn modulates the acoustic waveform which is received by a transducer located opposite to the transmitter. The same action occurs at station two. The two received waveforms are then demodulated and consequently cross-correlated to yield a time delay. Knowing the distance between the two stations and the time it took for the disturbance to travel from station to station, the velocity then is obtained. This instrument has been tested at the ANL solid/liquid test facility. A similar instrument is under development for solid gas media.

Acoustic Time-Domain Reflectometry (TDR) is a method of temperature measurement based on the principle that almost all materials exhibit a change in sound velocity with temperature. The method consists of transmission of an acoustic pulse through a thin wire in which several impedance discontinuities (notches) are incorporated; acquisition of the reflected signals from the discontinuities; and the measurement of time intervals between successive. reflections, which are then related to the average temperature of the corresponding segments by calibration. TDR probes can be used to monitor bed temperatures and gas temperature profiles in coal gas. 
The thin-wire acoustic temperature sensor was first envisaged by Bell Laboratories in 1957. Since then, several improved versions of acoustic sensors have been developed and tested in many applications due largely to the efforts of Lynnworth and his coworkers. A major application has been in the nuclear reactor fuel pin temperature measurements where high temperatures and lack of visual access preclude the use of conventional thermometers. Temperature profiling of up to sixteen zones using a single waveguide has been reported.

\section{UTtrasonic Thermometry}

In the light of its great potential for high temperature applications, Argonne National Laboratory has investigated the feasibility of using ultrasonic thermometry in coal conversion process. Thermocouples and other conventipnal thermometers proved to be inadequate because of the adverse environments prevailing in the reactors or combustors. The success of the ultrasonic thermometry, as the study concluded, is critically dependent on two factors: one on finding a good sensor material which will show good sensitivity to temperature and at the same time will withstand the hostile environment; and the other on developing appropriate electronics that will isolate and detect the echo peaks from the noise background. The noise sources are due to particle impingement and other mechanical peturbations inflicted on the sensor wire. The echo detection electronics of the available sytems, based on zero crossing or on direct peak detection, will not perform adequately in a noisy situation. At the present time ANL has developed a laboratory TDR unit with the necessary electronics and plans to test the instrument in a simulated gasifier environment.

\section{High Frequency Acoustic Leak Detection System}

ANL is developing leak location and signal processing methods, transducers and threshold detection equipment to develop a high frequency. Tests were conducted to determine spatial resolution of location system, investigate location accuracy as a function of leak placement, and accuracy of leak location. 
Water Level and Fuel-Failure External Monitoring

ANL has developed "HODOSCOPE". which is a multi-channel instrument routinely used in reactor safety instruments. This can provide non-intrusive detection of water level and detection of failed fuel in Nuclear Powerplants.

With respect to water-level monitoring, the gamma-ray hodoscope, subject to additional confirmation, appears to offer satisfactory performance at core and plenum elevations at full power and after reactor shutdown.

The tangential focusing of the collimator modules will aid in separating core and downcomer effects. If use can be made of vertical instrument pipe already in place, the system can probably be retrofitted without much difficulty. $A$ strong possibility exists that fuel failure can also be detected by an upper element of the same instrumentation. The threshold could be as low as a single-pin failure, but that will depend very much on actual background. In any case, the gamma-ray hodoscope compared to the neutron detection methods appear to have an improved potential in nuclear powerplants.

A practical arrangement for a gamma-ray hodoscope in a 7 ight-water reactor would consist of about two dozen identical collimated detector modules vertically arranged in the air gap or biological shield outside the pressure vessel. Ten detectors at $120-\mathrm{cm}$ vertical intervals would cover the full water height of a PWR. Water level and density changes would be evaluated by comparing responses at high and low elevations. The system would be operative at full power and after scram for many hours. Various possibilities exist for retrofit to existing reactors.

The goals would be water-level resolution of $15 \mathrm{~cm}$ and fuel-failure threshold corresponding to 1 pin, although actual values would depend upon specific conditions. These expectations are extrapolated from the large database derived from hodoscopes that operate under conditions which in most important respects are similar to those to be encountered in a light-water power reactor. 
In order to advance the gamma-hodoscope concept, additonal stages of calculations are needed, as well as experiments under more prototypical conditions such as LOFT and an operating power reactor. Subject to successful proof testing, such a nondestructible system should provide the type of reliable water-level dynamic information that could have averted the TMI-2 incident.

Leak Detection in Nuclear Power Generating Stations

The objectives of the leak detection program at ANL are: (a) develop a facility for the quantitative evaluation of acoutic leak detection (ALD) systems; (b) assess the effectiveness and reliability of ALD techniques; (c) evaluate a prototype ALD syste; (d) establish the sensitivity, reliability, and decisionmaking capability of a prototype system through laboratory testing; and (e) assess the effectiveness of field-implementable ALD systems. The program will establish whether meaningful quantitative data on leak rates and location can be obtained from acoustic signatures of leaks due to IGSCC and fatigue cracks in low- and high-pressure lines, and whether these can be distinguished from other types of leaks. It will also establish calibration procedures for acoustic data acquisition and show whether advanced signal processing can enhance the adequacy of ALD schemes.

No currently available single leak-detection methods combine optimal leakage detection sensitivity, leak-locating ability, and leakage measurement accuracy. For example, while quantitative leakage determination is possible with condensate flow monitors, sump monitors, and primary coolant inventory balance, these methods are not adequate for locating leaks and are not necessarily sensitive enough to meet regulatory guide gloas. The technology is available to improve leak detection capability at specified sites by use of acoustic monitoring or moisture-sensitive tape. However, current acoustic monitoring techniques provide no source discrimination (e.g., to distinguish between leaks from pipe cracks and valves) and no leak-rate information (a small leak may saturate the system). Moisture-sensitive tape provides neither quantitative leak-rate information nor specific location information other than the location of the tape; moreover, its usefulness with "soft" insulation needs to be demonstrated. Hence, leak detection techniques need further improvement in the following areas: (1) identifying leak sources through 
location information and leak characterization, to eliminate false calls; (2) quantifying and monitoring leak rates; and (3) minimizing the number of installed transducers in a "complete" system through increased sensitivity.

Significant progress has been achieved at ANL on acoustic leak detection (ALD). This has included monitoring at program at Watts Bar Nuclear Station. Characterization of acoustic leak signals from IGSCC, combined with information on acoustic background noise levels, allows acoustic signal-to-noise ratios to be estimated for a $10-i n$. Schedule 80 pipe as a function of distance from the leak. Under ideal conditions, leak rates as low as $0.1 \mathrm{gal} / \mathrm{min}$ may be detectable at distnaces on the order of $10 \mathrm{~m}$. Tests with various types of cracks indicate that quantitative correlations between leak rates and acoustic signals in the $300-400 \mathrm{kHz}$ band are possible for IGSCC. Recent cross-correlation results with simulated acoustic leak signals and $375-\mathrm{kHz}$ acoustic-emission sensors on $3-\mathrm{mm}-\mathrm{dia}$ waveguides indicate that correlations should be possible.

Preliminary tests have also been carried out at ANL to evaluate a breadboard ALD system that can carry out cross-correlation analyses (including averaging), monitor acoustic leak signals, and provide spectral information.

An evaluation of moisture-sensitive tape suggests that under the right conditions the tapes can detect leaks on the order of $0.01 \mathrm{gal} / \mathrm{min}$ when reflective insulation is used. Despite the sensitivity of the tapes, they do not provide quantitative leak data and a large leak at a distance can result in the same responde as a small leak near the tape.

The capability of acoustic techniques to detect, locate, and size leaks will be expanded at ANL. A breadboard ALD system witl be used to evaluate fieldimplementable concepts. Leaks larger than those examined thus far will be studied. These will include IGSCC, thermal fatigue, and, in particular, valve leaks. These data will form a more significant basis for estimating the sensitivity and reliability of ALD. 
The monitoring of Watts Bar Nuclear Station will continue. Additional background noise data will be acquired, along with data from any seal leaks appearing during reactor start-up procedures.

Non-Destructive Examination (NDE) of Cast Stainless Steel

Although the ASME code requires inspection of Cast Stainless Steel (CSS) piping, it has not been possible to demonstrate that current inspection techniques are adequate. For the near term, improvements that may increase the reliability of ultrasonic inspection include (a) the development of methods to establish the microstructure of the material (to help optimize the inspection technique), (b) calibration standards that are more representative of the material to be inspected, and (c) the use of cracked CSS samples for training purposes. For the long-term, it will be necessary to establish: (a) the variability of the microstructure of CSS, (b) the effect of microstructure on inspection reliability, (c) the degree of improvement possible with techniques and equipment designed specifically for CSS, e.g., focused transducers and lower frequencies than those used conventionally, and (d) qualification of requirements for CSS inspections.

Technical progress achieved at ANL has included:

- Use of acoustic techniques to determine velocity changes for isotopic and anisotropic material.

- Determine the behavior of ultrasonic of $45^{\circ}$ longitudinal beams to distinguish isotropic and anisotropic materials.

- Relationship between the microstructures and NDE will lead to reliable testing program by developing uitrasonic imagery. 
Results of these on samples from Battelle-Westinghouse and Commonwealth Edison do support encouragement of a breakthrough in this difficult problem in the following areas:

- Intragranular Stress Corrosion Level

-- Source of Corrosion

-- Source of Detection

- Leak detection of ultrasonic waves for application in NDE. 
Bibliography:

1. Acoustic Instrumentation by A. C. Raptis, Prog. Energy. Bosmut. Sci 1984, Vol 10, pp. 213-227.

2. Acoustic Velocity and Attenuation Measurements in Thin Rods with Application to Temperature Profiling in Coal Gasification Systems, N. Gopalsami and A. C. Raptis, IEEE Transaction on Sonics and Ultrasonics, Jan. 1984.

3. Instrumentation and Control for Fossil Energy-Quarterly Technical Progress Report, January-March 1984, ANL-FE-84-14.

4. Evaluation of Methods for Leak Detection in Reactor Primary Systems and NDE of Cast Stainless Steel, 12th Water Reactor Safety Research Information Meeting, October 22-26, 1984, Washington, D.C. by D. S. Kupperman, et.al.

5. Water-Level and Fuel-Failure External Monitoring by A. DeVolpe, Symposium on New Technology in Nuclear Powerplant Instrumentation and Control, November 28-30, 1984, Washington, D.C.

6. Components Technology, Argonne National Laboratory.

7. An Evaluation of Radiometric Techniques for Measuring Temperature in Coal Gasifiers by Gino J. Dilono, ANL/FE-83-4.

8. Application Potential of Advanced Instrumental Methods for On-Line Automated Composition Analysis of Solid-Liquid Fossil Energy Process Materials, Vol. II, Non-Nuclear Methods by C. L. Herzenberg, ANL/FE-83-22. 
Subject: Technology Transfer - Visit to Conference on Optical Fiber Communication and Optical Fiber Sensors

Date: $\quad$ February $11-14,1985$

Location: San Diego, California

BACKGROUND TO FIBER OPTIC DEVELOPMENT

Prior to 1970, the fiber optic technology was laboratory based, primarily because of the difficulty in obtaining glasses that could transmit light with minimal absorption, while forming a practical coazial clad with the correct differential refractive index. The goal for reaching practicality was to achieve an attenuation rate of less than $20 \mathrm{~dB} / \mathrm{Km}$ of fiber cable.

In 1970, glass researchers at Corning produced a glass composition which allowed this goal to be achieved. Glass fiber could now be considered a viable alternative to coaxial cable for long distance communications. The parameter used to define communication ability is the rate of information transfer per kilometer of fiber. In 1970, the optical transmission rate achieved $10 \mathrm{Mbits} \mathrm{Km} / \mathrm{sec}$; at the conference, it was announced that Bell Research Laboratory workers had achieved $1.366 \mathrm{Terrabit} \mathrm{km} / \mathrm{sec}$. Current attentuation factors are of the order of $0.1 \mathrm{~dB} / \mathrm{Km}$.

To place these figures in context, this allows all of the current transAtlantic traffic to be carried on a single fiber without the need for repeaters. If this change in capacity is plotted, it corresponds to a doubling of capacity each year (figure 1). The values shown on the diagram were obtained in laboratory demonstrations. If field test demonstration of performance is plotted onto the same diagram, a shift to the right is observed. This indicates that there is a three year delay between demonstration in the laboratory and demonstration in the field.

The amount of cable installed installed in the USA is growing rapidly. If one assumes that each cable operates at the modest rate of 4 to $5 \mathrm{mb} / \mathrm{sec}$, then the capacity being installed each year is roughly equivalent to the total Bell 
System network that existed in 1980. In effect, there is a duplication of the 1980 Bell System toll network each year.

Current communication research thrusts are improvements in the practical application of fiber optics, such as cable splicers and connectors to couple the long haul cables to individual subscribers. Connections must be made with minimum light attenuation to prevent the need for repeaters. Although the hardware problems are difficult, the most severe problems are likely to be software oriented, such as man-machine inteface. On a list produced documenting the expected problem areas, it looks remarkably similar to lists for nuclear power progress.

Concurrent with the development of the fiber cable has been the development of the light source devices. Two major types are currently available, i.e., light emitting diodes (LED), and lasers. Both solid state and gas lasers are available, the latter producing the higher optical intensity. Applied research programs are attempting to improve the efficiencies of launching the light into the fiber optic cable. Detectors are also in an advanced stage of development. In listening to some of the authors, one got the impression this aim was to achieve detection of a few photons. The current lower limit is approximately 10 photons, the inherent noise level.

The claim was made that with the current technology, it was now feasible to transmit across the AtIantic using an LED. No repeaters would be required, but cables would have to be spliced to make up the length of cables required. The cost of the glass fiber cable is now of the order of cents/foot. Commercial/industrial applications require extensive protection of the fragile fiber. Cables are commercially available with armor, stainless steel sheathing guaranteed to be "gopher proof". There was no indication that installing commercial/industrial quality fiber optic cable was any more difficult than installing copper cable. Extensive networks of long-haul communication cables already exist in the U.S. Cables will be laid across the Atlantic and Pacific oceans in the near future by a consortium of inter-national companies. 
Light transmission through the fiber is either multi-mode or single mode. Minimum light absorption takes place in glass at the red end of the spectrum. Earlier systems used a "window" in the absorption band at approximately 800 nanometers $(n M)$. Current technical advances are moving towards 1300 and 1500 nM wavelengths. Most of the earlier developments used multi-mode light transmission, in which a band of wavelengths were launched and detected. About two years ago, the trend changed to single mode frequency transmission. Single mode transmission has advantages in both communication and fiber optic sensor technology.

\section{CURRENT FIBER OPTIC DEVELOPMENT}

Present day telecommunication networks can be separate into three basic segments:
a. Long and short haul -- between switching centers.
b. Feeder
-- between the switching center and the remote distribution point outside the customer.
c. Subscriber
-- local area network, or an individual who connects to the external network.

It is the first of these elements that has driven the development of the fiber optic technology. Although driven originally by telephone communication, the influence of video transmission is now providing its bias. Each of these three segments has its own characteristics, both technical and economic.

Fiber optic technology has strongly penetrated the long haul terrestrial and submarine market. It is competitive in price and the penetration will continue. However, the break-up of the Bell System and the appearance of long haul competition will tend to slow the current pace of development. Market competition will reduce the amount that $c$ an be invested in $R \& D$. 
For the short haul and feeder application, the technology is available and competitively priced to replace copper. This is seen in the nuclear industry applications where fiber optic links are installed between process computers and the technical center at the Palo Verde, Arizona site. Data transmission rates could only be practically and economically achieved by fiber optic cable's capacity to perform at ultra-high rates. This trend towards fiber optics will continue without extensive R\&D efforts.

Extensive, and expensive, trials of fiber optic based subscriber systems are underway, principally in Europe and Japan. For such systems to achieve market penetratio, further developments in hardware, and especially softwre, are needed. Inexpensive splicing and coupling techniques, receivers, and possibly, transmitters must be developed to become competitive with copper based systems. The broad bandwidth and high data transmission rates make video transmission (i.e., cable TV and videophone) feasible, concurrent with complex interconnection for voice (i.e., neighbors able to have conference calls without using the feeder networks), and data interchange (videotex, banking., shopping, etc.). However, many authors question whether this is a valid market, pointing out the fiasco with the Bell videophone service and the poor response to videotex type services in the U.S.

A paper from the French CNET (Centre Nationale d'Etudes des Tellecommunication) organization described experience gained installing a 1500 subscriber system in Biarritz. It required 7,000 cable splices, producing a loss of less than $0.03 \mathrm{~dB}$, and after all interconnections were completed (2 splices and 2 or 3 connections), the total attenuation was in the range 4 to $5 \mathrm{~dB}$. If 1.3 uM cable was used, it was predicted the loss would be about $2.5 \mathrm{~dB}$. In order to install such a network, fiber production and cabling techniques were developed to produce the low cost materials. These techniques would not produce long haul or short haul systems, but are quite satisfactory for local area. networks. Instead of producing a single fiber, the normal production approach, seven fibers were drawn simultaneously and immediately installed into the external sheathing. This production technique resulted in 30 to $40 \%$ direct cost reduction, and probabiy significant indirect cost reduction because of the integrated production approach. No problems were experienced with splices and connectors, but more work is necessary to make them easier 
and cheaper. A second network is being installed in a Paris suburb connecting 150,000 subscribers, and in 1986-7 a system of 1.5 million subscribers will be started. The CNET organization predicts the system will pay for itself within 5 to 6 years from subscriber fees.

Almost certainly these types of programs will result in fiber optic components for interconnecting cable, providing data distribution (receivers, transmitters, demodulators, multiplexers, splicers, connectors, etc.) becoming inexpensive and practical. AT\&T were showing prototypes of plastic wall and desk boxes similar to those currentiy used with copper, and many other commercial/industrial suppliers were showing connectors, including RS-232C and 4MA-to-20mA transmitting and receiving interfaces for sensors and computers.

\section{Optical Fibers for Harsh Environments}

Perhaps the greatest deficiency in the fiber optic technology is the relatively low high-temperature limits $\left(70^{\circ} \mathrm{C}\right)$ for most sensors and transmission products. Again, this is likely to be rectified by the pressures of the military community for components to operate at temperatures up to $200^{\circ} \mathrm{C}$.

Hughes Research Laboratories reported on tests of fiber optic cables exposed to a jet fuel fire, or to resistance heaters at temperatures up to $650^{\circ} \mathrm{C}$. In the worst case test, jet fuel flame, the fiber survived for 40 minutes. These cables are designed with sheaths that are fire resistant, and do not emit hazardous smoke or fumes that are toxic to personnel in the area. An optical signal at 0.85 UM was transmitted continuously, and the cable considered failed when the transmission dropped to zero. Organic and metal coated fibers fail within approximately two minutes, but these special cables can operate at temperatures in excess of $600^{\circ} \mathrm{C}$, be quenched, and returned to $600^{\circ} \mathrm{C}$ and survive for relatively longi timescales (40 minutes). The cables are quite small in diameter $(2.44 \mathrm{~mm})$, and have ceramic and metal coatings and sheaths to provide the protective properties.

The main culprit in degradation of current optical fibers is hydrogen, or perhaps the hydroxyl ion. If fibers are heated in hydrogen at one atmosphere, the transmission falls, the loss being dependent on temperature and fiber 
type. Losses of $10 \mathrm{~dB} / \mathrm{Km}$ occur in fibers heated to $200^{\circ} \mathrm{C}$ within about one hour. Two mechanisms are postulated--absorption of light by the hydrogen molecules which diffuse into the fiber, and hydroxyl absorption loss from the chemical reaction of the hydrogen molecule and the glass. If the hydrogen can diffuse out of the glass, then an equilibrium condition can exist, with losses in typical cables predicted to be of the order of $0.5 \mathrm{~dB} / \mathrm{Km}$ over 25 years.

One potential source of hydrogen is the cladding material. Tests with various coatings on the fiber, prior to cladding, show significant gains in reducing fiber deterioration both optically and mechanically. An extensive program was funded at Hewlett-Packard Laboratories by the Naval Research Laboratories (NRL). A vapor deposited silicon oxynitride coating produced significant resistance to environmental degradation, and commercial versions of the fiber are available.

Los Alamos National Laboratory and military research groups such as NRL are pursuing research into optical fibers which do not degrade their optical or physical properties in a radiation environment. Radiation can cause luminescence, increase absorption, cause dimensional modifications, induce thermoluminescence, and change mode dispersion and attenuation characteristics. Radiation damage is usually irreversible to some degree.

There is a relation between the hydroxyl ion concentration and the radiation resistance; it can differ at high and low wavelengths. General discussions with attendees at the conference (G. Sigel, NRL, F. Allard, NUSC, R. Walters, $U$ of Central Florida) suggests that radiation resistance fiber materials are available and liekly to become a standard product sometime in the future. The effect of radiation on transmitters and receivers is also under study.

Most of the current work on radiation resistance of fibers and claddings is directed towards military applications that cause radiation damage. Differences may appear when nuclear power plant radiation spectra are considered, but the major concepts of radiation effects on fiber will become available from ongoing technology programs. 


\section{FIBER OPTIC SENSORS}

The comment was heard quite often that each "problem" associated with fiber optic transmission becomes an opportunity to invent a sensor. Micro-bending of the fiber causes attenuation, a problem in light transmission, but when attenuation is correlated with the cause of micro-bending, it becomes a sensor. Similarly, radiation can cause fluorescence and permanent damage, introducing noise or signal transients in communication, but as a sensor it becomes a radiation measuring device or dosimeter.

The detection of these anomolies is achieved in several ways, from small amplitude changes to sophisticated frequency and phase modualtion schemes. In order to use the frequency dependent sensors, single mode fiber technology is essential, and the current directions in communication research will have a beneficial impact on sensor technology. Some of the more sophisticated sensors/transducers rely upon the properties of the coatings and claddings surrounding the fibers. Claddings are available which are sensitive to magnetorestriction, piezoelectric polymers, thermally sensitive, or compliant to respond to acoustic or static pressures, an dmetallic glasses which are sensitive to magnetic fields.

Many inventive and creative approaches have been described for measuring most of those parameters of importance to nuclear power. Although it might be instructive to attempt to describe some of the more exciting concepts, it would only emphasize the main problem in the fiber optic sensor field. The technology is in its infancy, laboratory and university driven, with almost zero penetration into the industrial monitoring environment.

Besides introducing fiber oiptic sensors for monitoring normal process control parameters, some of the more exotic approaches will amost certainly be developed because of their added capability or potential to reduce lifetime sensor system costs. Not all of the sensors in the literature will become commercially available.

One aspect of fiber optics sensor technology which will provide significant changes in measurement technology is an ability to make distributed parameter measurements with a single fiber. For example, optical time domain 
reflectometer (OTDR), the exact location of the disturbance along the fiber $c$ an be measured. More complex measurments will also provide the amplitude of the disturbance. Another aspect of fiber optic technology that will impace measurement technology is the ability to remotely monitor the active device. A long fiber can provide both illumination and sensor output, if necessary, from the conrol room area.

Perhaps the most telling paper presented was the invited paper from the major industrial company in the U.K., Imperial Chemical Industries. The paper title was "Fiber-0ptic Sensors Fit the Chemical Industry". Imperial Chemical Industries, driven by the cost of maintaining its existing instrumentation, started the search for technologies with cheaper total cost four years ago. The decision was made to pursue optical fiber technology. For thriry minutes during the conference, industrial type sensors to monitor flow, pressure temperature, and simialr process parameters wre presented. The sensors were in housings and structures expected for use in the petrochemical industries. Quite often they were a marriage of a commecial structure, such as a Kent pressure gauge, with a fiber optic detector; in this instance, detecting the movement of the diaphragm. When asked during the question period how many fiber optic devices were actually in use in Imperial Chemical Indusries facilities, the answer was "none!" They hope to initiate field trials within the next year, to prove that the instruments are reliable and begin diffusion of fiber optic instruments sometime in the future as experience is gained. A telephone check with a major inustrial instrument supplier suggests that Imperial Chemical Industries might even be more advanced than the situation in the U.S. 
SUBJECT: TECHNOLOGY TRANSFER - VISIT TO GAS COOLED REACTOR ASSOCIATES (GCRA)

Date: $\quad$ March 1, 1985

Location: San Diego, California

Contacts: Graham Jones, Manager, Planning and Technology David Frederick, Senior Project Engineer Fred Swart (part-time)

A. BACKGROUND: Gas Cooled Reactor Associates (GCRA) and High Temperature Gas Reactor (HTGR)

GCRA was established in 1978 by six utilities. Utility support has grown to represent over $35 \%$ of installed generation capacity in the United States of America. This utility/user organization is responsible for guiding the development of the High Temperature Gas-Cooled Reactor (HTGR). In addition, Gas Cooled Reactor Associates (GCRA) provides overall National program support services to the United States Department of Energy. Gas Cooled Reactor Associates also interfaces with the Electric Power Research Institute (EPRI) to transfer technology from their High Temperature Gas Reactor (HTGR) programs.

The High Temperature Gas Cooled Reactor is an advanced second generation nuclear power system. It is cooled with pressurized helium, moderated and reflected with graphite, and fueled with individually coated ceramic particles. The micro-sphere fuel particle, 800 to 880 microns diameter, has concentric pyrocarbon and silicon carbide layers providing a tough coating, reducing particle failure rates and fission product to acceptable levels at temperatures up to $1600^{\circ} \mathrm{C}\left(2900^{\circ} \mathrm{F}\right)$. In the "prismatic core". design these particles are mixed with a binder and formed into fuel rods, which are loaded in vertical holes in a prismatic graphite block. In the "pebble core" design the particles are molded into a six-centimeter diameter graphic sphere. 
The unique ceramic coated fuel design and use of inert helium gas as coolant provide the HTGR with inherent safety features. Helium gas is neutronicaly and chemnically passive, so there are no reactivity effects or chemical reaction with the fuel. The high heat capacity and low power density of the core results in very slow and predictable core temperature transients; even a loss of coolant produces a very slow temperature increase, allowing hours for the operator corrective action. Passive decay heat removal is by radiation, conduction and natural circulation. Below $1066^{\circ} \mathrm{C}$ all fission products are totally contained within the ceramic coated particles. For a cylindrical core geometry with 4 watts heat generation per $\mathrm{cc}$, and a maximum design power generation of $250 \mathrm{MWT}$, the maximum fuel temperature does not exceed $1600^{\circ} \mathrm{C}$ resulting in an inherentiy safe reactor. The high retention of fission products within the fuel particles, and the neutronically inert coolant results in low concentrations of radioactive wastes in the reactor plant process streams (typically one or more orders of magnitude lower than current LWR designs.

The inherently passive features of the High Temperature Gas Reactor (HTGR) reduce the need for special instrumentation and control systems. However, there are some specific sensor systems that are unique to the High Temperature Gas Reactor (HTGR). These are covered in subsequent sections.

High Temperature Gas Reactor systems are being actively pursued in many parts of the world, including Germany, UK, Japan, USSR. The first United States prototype High Temperature Gas Reactor was Peach Bottom I, built as part of the USAEC Power Reactor Demonstration Program. The $40 \mathrm{MWz}$ reactor (115 MWT) had a core outlet temperature of $1342^{\circ} \mathrm{F}$ and 8.3 watts/cc thermal generation rate. Peach Bottom I was operated from June 1967 to October 1974, and achieved an average NSSS availability of $88 \%$ excluding planned shutdowns for Research and Development programs. A 330 MWe demonstration reactor followed, Fort St. Vrain. It went critical in January 1974 and nine years later had produced almost 4 billion kilowatt hours of net electrical energy. Unlike Peach Bottom I the demonstration reactor had low availability. Temperature fluctuation in the core resulted in a $70 \%$ power limit from January until November 1981. Water injection into the helium gas from the helium circulator bearings resulted in plant shutdown or limited operation. 
The High Temperature Gas Reactor program in the Federal Republic of Germany (FRG) has produced a reactor core design in which the six-centimeter fuel/ graphite spheres are continuously loaded and discharged through the core to provide on-line refueling. A 15 MWe protoptye plant has achieved an overall availability of $68 \%$, peaking at $92 \%$ in 1976. For extended periods of time the core outlet temperature was maintained at $1740^{\circ} \mathrm{F}$. A 300 MWe demonstration plant achieved criticality in September 1983, with commercial operation expected in 0ctober 1985. An ability to operate at high core outlet temperature provides an opportunity for advanced electrical generation and direct process heat application.

The FDR and UK programs on gas cooled reactors has advanced the technology; and provides opportunities for technology transfer programs as well as commercial sources for plant components and fuel.

\section{B. SPECIAL SENSOR TECHNOLOGY REQUIREMENTS FOR HIGH TEMPERATURE GAS REACTOR}

\section{Moisture Monitor}

Primary sources of moisture in the helium are leakage in the steam generator and leakage from the gas circulator bearings. The bounding condition would be water injected from a double ended guillotine tube failure. A guillotine failure injects $10 \mathrm{~kg} / \mathrm{sec}$ up to $30 \mathrm{~kg} / \mathrm{sec}$, depending upon the axial location in the helical coil, once-through steam generator. Under fault conditions the moisture level can reach many thousands of parts-per-million H20-in-He. The normal moisture level is in the range 0-1 ppm; and a total range instrument of 0-10 ppm would be used for monitoring during normal operation. The helium gas is at a pressure of approximately 1200 psia.

Two types of High Temperature Gas Reactor are being considered, a large prestressed concrete reactor vessel PCPV unit and a small modular design with a steel pressure vessel. Moisture oxidizes the graphite structure, but the rate of oxidation is low and even a guillotine tube failure would not require a core rebuild. The impact of water injection in the steel pressure vessel modular High Temperature Gas Reactor is more severe. Water entering the core causes a positive increase in reactivity requiring control rod insertion to 
prevent overheating since the moisture softens the spectrum. In the large PCPV HTGR the water injection can be terminated before a reactivity problem occurs.

The High Temperature Gas Reactor designers would prefer the moisture monitor to have a response time of less than 11 seconds. Among other benefits this allows the particular gain loop with the problem to be identified. The best sampling points would be the steam generator outlet. Current moisture monitors use gas stream sampling techniques, introducing an inherent delay in the moisture monitor response time.

Following a problem with the steam generator or bearings the reactor is shutdown. A possibility exists that water may have been condensed at the bottom of the core. Fort St. Vrain High Temperature Gas Reactor does not have a drain line, and checking for water deposition has been a problem area. Future reactors will include a drain, but it is not impossible for water to be deposited at some location. Can a detection system/sensor provide confirmation that no water pools exist in the system?

\section{Reactor Core Temperature Measurements}

Although the reactor design has a large temperature separation between operating temperature and fuel failure problems the power of the reactor is limited by the gas temperature across the core. It is possible to adjust the gas flow through the different sections of the core and provide a balanced core temperatuire distribution. Long, approximately 40-foot robust thermocouples are inserted by a tortuous path into the core to monitor the temperature. Regular calibration of these in-core thermocouples is required, and achieved by inserting calibrated thermometers into the reactor.

The reactor designers are uncertain about the thermocouples lasting up to 40 years, expecially in terms of accuracy and stability of indication. If they had to be replaced it would be a major undertaking. An alternative approach to monitoring temperature levels would provide design assurance of plant availability. 
Since the actual temperature of the gas stream is not important, rather the gas temperature is constant and does not exceed a maximum, a BI-STATE indicator was suggested as an alternative. If an inexpensive transducer was available which produced a digital switch signal as a function of temperature, the gas flow/power could be adjusted until the transducer flipped into the high temperature state. The High Temperature Gas Reactor designers welcomed this approach and would be open to this technique of temperature control, and balancing core temperature distribution.

\section{Core/Graphite In-Service Inspection (Robotics)}

Any oxidant in the gas stream, including moisture, will react with the graphite. It is necessary to physically inspect the core graphite blocks, especially those that are at the base of the core. In-core measurement of strain and of oxidation rate are needed. Visual inspection of the graphite blocks is required, and the ability to scrape the surface and obtain samples. It appears to be an ideal robotic application.

Robotic applications are also indicated in the pebble bed fuel handiing. Remote maintenance, transportation sysstems to move spheres, pass through a sorting process, and return to the reactor, and removal of poison spheres from the fuel flow was suggested as areas for consideration. The Federal Republic of Germany (FRG) program has produced robotics for the 'PHTR' and 'ATR' high temperature gas reactors and it is possible that a technology transfer would be fruitful. In the manufacturing process increased efficiency might occur if certain processes were mechanized, including inspection of fuel particle coating thickness and vibration screen to separate non-spherical particles.

\section{Liner Integrity Check}

The inert helium gas is neutronically transparent and leakage from the reactor vessel is not a safety problem, but could become an economic factor if leakage is significant. Current techniques for monitoring the welded steel liner are based on pressure decay. With the large and complex geometry such techniques are not particularly accurate, small changes in temperature providing sufficient "noise" in the pressure measurements to mask small leaks. A leak of 
greater than $1 \% /$ year is a significant economic loss. The PCRV is maintained at $150^{\circ} \mathrm{F}$, by cooling during operation and by heating during shutdown. Thermal stability to measure the pressure decay is difficult.

Balance of Plant Instrumentation and Control

Following most reactor instrumentation and control specialists concerns were expressed on accuracy and stability of sensor systems monitoring process flow parameters. Similar concerns to those expressed in the report on the EPRI seminar were expressed. 
SENSOR VENDOR SURVEY

1. TITLE - Thermistors

2. APPLICATION - Temperature Measurement

3. THEORY OF OPERATION

Thermistors are temperature sensitive passive semiconductors which exhibit a large change in electrical resistance when subjected to a relatively minute change in body temperature. Negative temperature coefficient thermistors decrease in resistance when subjected to an increase in body temperature. Their extreme sensitivity to minute temperature changes enables them to perform many unique functions heretofore impossible with standard electronic components.

The resistance of a thermistor is solely a function of its absolute body temperature. When testing for resistance accuracy it is essential that the surrounding environmental temperature is held at a constant and power dissipated in the thermistor is low enough to insure no "self-heating". A thermistor will obey Ohm's Law, and current flow will be proportional to voltage applied providing insufficient power is dissipated in the thermistor to "self-heat" its temperature above that of the surrounding ambient. However, should the applied voltage be increased sufficiently to cause excessive power to be dissipated, the thermistor will "self-heat", causing a reduction in resistance and an increase in current.

\section{PLANT APPLICATIONS}

a. Measurement of differential temperature such as in heating, ventilation an air conditioning.(HVAC) systems, where it is desirable to measure one temperature with respect to another. 
5. LITERATURE SEARCH

At this time a literature search is $n$ progress, but no significant relevant material is available.

6. MANUFACTURERS SURVEY

a. The following listed manufacturers provide thermistors and assemblies:

Alison Control, Inc., Fairfield, $\mathrm{NJ}$

Ametek, Inc., Rodan Div., Anaheim, CA

Canadian Thermostats and Control Devices Ltd., Montreal, Canada

Cole-Parmer Instrument co., Chicago, IL

Conax Buffalo Corp., Buffalo, NY

Dale Electronics, Inc., Columbus, Div., Columbus, NE

Daytronic Corp., Miamisburg, $\mathrm{OH}$

Extech International Corp., Instrument and Controls, Waltham, MA

Fenwal Electronics Div. of Kidde, Inc., Fra mingham, MA

Fenwal, Inc., Div. Kidde, Inc., Ashland, MA

Flo-Tech, Inc., Mundelein, IL

$\mathrm{H}-\mathrm{B}$ Instrument $\mathrm{Co}$. , Inc., Chicago, IL

Instrulab, Inc., Dayton, $\mathrm{OH}$

Keystone Carbon Co., Thermistor Div., St. Marys, PA

Love Controls Corp., Wheeling, IL

M-C Products, , Scottsdale, AZ

Mamac Systems, Minneapolis, MN

Midland-Ross Corp., Electronic Connector Div., Cambidge, MA

Midwest Components, Inc., Muskegon, MI

Newark Electronics, a Div. of Premier Industries, Chicago, IL

Non-Linear Systems, Div. of Kaypro Corp., Solana Beach, CA

Omega Engineering, Inc., Stamford, CT

Pacer Industries, Inc., Chippewa Falls, WI

Piezo Electric Products, Inc., Metuchen, NJ

Precision Digital Corp., Watertown, MA

RCD Components, Inc., Manchestr, $\mathrm{NH}$ 
RDF Corp., Hudson, NH

Sensor Scientific, Inc., Fairfield, NJ

The Singer Co., Controls Div., Schiller Park, IL

Solitech, a Div. of Indus. Engineering \& Equipment Co., St. Louis, M0

Stratford Control Systems, Inc., Stratfrd, CT

Sunshine Scientific Instruments, Philadelphia, PA

Temp-Pro, Inc., Northhampton, MA

Thermologic Div., of Dytron, Inc, Waltham, MA

Thermometrics, Inc., Edison, $\mathrm{NJ}$

b. The following manufacturers have supplied literature:

Ametek-Rodan Division, Anaheim, CA

Omega Engineering, Inc., Stamford, CT

Fenwal Electronics, Framingham, MA 
1. TITLE - Ultrasonic and Acoustic Instrumentation

2. APPLICATION - Flow Measurement

3. THEORY OF OPERATION

There are three primary types of ultrasonic and acoustic techniques to measure flow. In the first type (time-of-flight meters), a high-frequency (approximately $1 \mathrm{MHz}$ ) pressure wave is beamed at an acute angle across the pipe. The time required for the wave to reach the opposite wall depends on whether it is moving with or against the flow and on the speed of sound through the liquid. Flow-rate information is obtained from the measured time. In the second type, referred to as the Doppler flowmeter, the beam does not traverse the pipe but is reflected back to a detector by particulate matter moving with the flow. The difference between reflected frequency and fixed transmitted frequency implies the flow rate. The third type of ultrasonic flowmeter is based on the concept of contrapropagating transmission in which sound waves are propagated alternatively in opposite directions between transducers mounted on either side of the pipe. Because the upstream signal is speeded up by the moving fluid, the alternate bursts yield a frequency difference which is electronically translated into a flow measurement.

\section{PLANT APPLICATIONS}

Ultrasonic and acoustic techniques may also be usable to measure temperature, level, density, position and vibration. Acoustic and ultrasonic techniques are attractive because they are nonintrusive, easy to apply, and have inherently fast response. The technique has primarily been used in a variety of applications for measuring flow.

Time-of-flight and contrapropagating flowmeters are generally used in clean liquid applications, where the ultrasonic beam is not attenuated or continuously interrupted by fluid particles. Claimed accuracies range from $+\underline{1}$ to $+\underline{4} \%$, depending on design. 
The Doppler-type flowmeter relies on small particles or impurities in the flow but has also been used successfully on many almost-clean as well as very dirty streams. Because of the velocity profile, accuracy depends on particle concentration and distribution. Accuracy is also influenced by the relative velocity between particles and fluid.

Since nothing extends into the pipe to obstruct the flow of liquid there is no pressure drop associated with such instruments. There are no orifice plates or other appurtenances at the point of measurement which require periodic inspection, maintenance, or replacement.

Maintenance is minimized due to the fact that there are no moving parts to wear out or be damaged. Calibration is generally not required because parts do not change characteristics with time. In addition, material deposits on the transucer faces do not affect flow measurement accuracy.

Design of the system using ultrasonic and acoustic senosrs provides high precision over wide flow ranges. Such devices are also essentially plugged-in. This type of construction also facilitates replacement of defective modules.

\section{LITERATURE SEARCH}

The following papers were reviewed:

a. Latest Level Sending Systems Enhanced by Microprocessor Influence by S. J. Bailey--Control Engineering, November, 1984.

b. Acoustic Monitoring of Power Plant Valves, Electric Power Research Institute (EPRI)--Report RP1246.

c. State-of-the-Art of Acoustic Instrumentation for Coal-conversion Plants by A. C. Raptis and T. K. Lau, Argonne National Laboratory. 


\section{MANUFACTURERS SURVEY}

a. The following listed manufacturers provide ultrasonic flow sensors:

ULTRASONIC, DOPPLER

Enterra Instrumentation Tech. (formerly Exidyne), Exton, PA Hycal Engineering, a Unit of General Signal Corp., El Monte, CA Pacific Meter, Inc. Point Roberts, WA Polysonics, Inc. Houston, $T X$ Smith Meter, Inc. Erie, PA J. W. Sweet Co., Chapen, SC Texas Nuclear Corp., a Div. of Ramsey Engineering, Austin, TX ULTRASONIC, OPEN-CHANNEL

BIF, A Unit of General Signal, West Warwick, RI Bonitron, Inc. Nashville, TN Brooks Instrument Div. of Emerson Electric Co., Hatheld, PA Enterra Instrumentation Tech (formerly Exidyne), Exton, $P A$ Ferranti O.R.E., Inc., Accusonic Div., Fairmouth, MA ISCO, Environmental Div., Lincoln, NE Sarasota Automation, Ltd., Hampshire, England, UK Sparing Instruments Co., Inc., El Monte, CA

J. W. Sweet Co., Chapin, SC

UL TRASONIX, THROUGH-BEAM

BIF, A Unit of General Signal, West Warwick, RI Ferranti, 0.R.E., Inc., Accusonic Div., Falmouth, MA Smith Meter, Inc. Erie, PA Sparing Instruments Co., Inc. El Monte, CA Westinghouse Electric Corp., Oceanic Div., Annapol is, MD Automation Industries Inc., Sperry Products Division Badger Meter Inc., Precision Products Division Bernhard, Inc. 
Endress \& Hauser, Inc.

Gow-Mac Instrument Company

Gulton Industries, Inc., Servonic Division

Inventron Industries, Inc.,

J. B. Engineering, Inc.

Koontz-Wagner Electric Co., Inc.

Krautkramer-Branson, Inc.

Leeds \& Northrup

Instruments General Signal, Unit of Magnaflux Corporation

Massa Products Corporation

National Sonics Division

Xertex Corporation

Sam Tec Incorporated

Sonic Instruments Incorporated

Stevens International

U.E. Systems Incorporated

WESMAR Industrial Systems Division

b. Pertinent literature was received from the following manufacturers:

Badger Meter Co., Tulsa, Oklahoma

National Sonics Corp., Farmingdale, NY

ITT Banton, City of Industry, CA 
1. IITLE - Radio Frequency Techniques

2. APPLICATION - Level Measurement

3. THEORY OF OPERATION

Radio-frequency based level measuring instruments use static sensing probes which are suspended in the vessel containing the interface level to be measured. The output of a low voltage radio frequency oscillator is applied to the probe. Minute current will flow between the probe and the vessel walls. The amplitude and phase characteristcs of these currents will depend on the characteristics of the materials in the vessel. Variations in level of the interface between the materials will cause variations in the current flow. This current is applied to a bride circuit. The resultant output voltage after demodulation and circuit compensation provides a measure of the interface level.

\section{PLANT APPLICATIONS}

The instrument operation remains relatively unaffected by sticky conductive materials that build-up on the sensing element or by high temperatures and pressures in the vessels. The properties are very veneficial in their application in measuring sodium levels in a liquid metal reactor $\mathrm{plant,} \mathrm{undergroung} \mathrm{tanks,} \mathrm{tanks} \mathrm{that} \mathrm{contain} \mathrm{corrosive}$ liquids such as boric acid, etc.

\section{LITERATURE SEARCH}

At this time a literature search is in progress, but no significant relevant material is available. 


\section{MANFACTURERS SURVEY}

The following listed manufacturers provide radio frequency type level. sensors:

Accuracy Corp., Columbus, Ohio

Delta Controls Corp., Shreveport, LA

Zi-Tech Instrument Corp., Palo Alto, CA

Drexelbrook Engineering Cor., Horsham, PA

Hanmor Co.., Inc., Chicago, IL

George Kelk Ltd., Don Mills, Ontario, C

Monitrol Bin-Level Co., Inc., Tyler, TX

Omron Electronics, Inc., Schaumburg, IL 
1. TITLE - Piezoelectric Instrumentation

2. APPLICATION - Flow and Pressure Measurements

3. THEORY OF OPERATION

Piezoelectric instruments operate on the basis of piezoelectric effect in the crystals. When the crystal elements are strained by an external force, displaced electrical charge accumulates on opposing major surfaces, forming a voltage signal according to the law of electrostatics. The displacement of electric charge occurs due to the deflection of the crystal lattice. The magnitude of the voltage produced is proportional to the pressure or force applied to the crystal.

Based on the above principle, several flow and pressure measuring instruments have been developed, which are discussed below:

\section{a. Flow Measurement:}

Vortex shedding flowmeters utilize piezoelectric crystals in measuring flow of fluids in a pipeline. Vortex shedding is the name given to the natural effect which occurs when a fluid flows around a non-streamlined object. The flow, unable to follow the shape on its downstream side, separates from the surface of the object leaving a highly turbulent wake. Each eddy or vortex that forms in this wake first grows and then become detached or shed from the object. In the vortex shedding flowmeter, a triangular-shape flow element (a bluff body) extends across the pipeline. Downstream of the bluff body, von Karman vertices form and shed alternately proportional to the rate of flow on either side of that triangular flow element which is prependicular to the stream of flow. Pressure on a series of these vortices so generated causes an oscillating spool inserted in the bluff body to produce an alternating stress. This stress gives the piezoelectric sensor located in the bluff body, a change in its electric 
charge in the converter. This change in the form of a train of voltage pulses are counted to measure the flowrate. As the flow varies, the speed with which each vortex forms and sheds varies at the at the same rate. As a result, the number of vortices generated and consequently the number of voltage pulses produced per second are proportional to the flow rate. Based on the dimensions of the flow element and the pipeline, the number of pulses generated per unit volume provides the volmetric flow.

Piezoelectric crystals are also used in ultrasonic flow meters, which are used to measure the fluid flowing in a pipe. These flowmeters operate on the principle of measuring the velocity of sound as it passes through the fluid flowing in a pipe. Piezoelectric crystals are used as transmitters to send accoustic signals through the fluid flowing, and as receivers to receive the signals transmitted. Refer to "Ultrasonic and Acoustic Instrumentation" for more details on the operation of these instruments.

b. Pressure Measurement:

Quartz crystal pressure transducers operate on the principle of providing an analog signal output proportional to the applied pressure or force. These transducers are used to measure transient or repetetive pressures relative to the initial pressure conditions, because the accumulated charge in the piezoelectric quartz crystal as a result of the transient condition is discharged into an AC coupled circuit. Repetetive transients produce repetetive charge accumulations, and hence repetitive signal outputs.

The transducer assembly consists of a crystal element, an amplifier and a floating clamp unit. The transducer assembly is installed flush or recessed through a threaded post into the pipeline or the equipment in which the dynamic pressure is 
to be monitored. The floating clamp isolates the instrument against strain and facilities installation and removal of the sealed transducer assembly. In high temperature application (above $600^{\circ} \mathrm{F}$ ) either the amplifier needs to be installed away from the equipment, or a circulating cooling medium needs to be supplied to the transduer to protect the electronics in the amplifier from damage due to high temperature. 
4. PLANT APPLICATIONS

Vortex shedding flowmeters have been in existence for a long time, and have been used in several flow measurement applications in power plants. Specifically, vortex shedding flowmeters can be used in gases, steam and liquid flow measurements, with process conditions ranging from $-40^{\circ} \mathrm{F}$ to $600^{\circ} \mathrm{F}$ and up to $725 \mathrm{psig}$. These instrument operates on 14 to 45 VDC external power supply, providing an output of either 4-20 madc current pulses ( 1 millisecond) or 4-20 madc analog current linear with flow. The signal outputs can be transmitted up to $3000 \mathrm{ft}$. for computing, indicating or controlling instruments. Since the instrument utilizes piezoelectric quartz crystal to detect minute changes in the stresses of the oscillating spool, the instrument can be characterized by high sensitivity and percise flow measurements over a wide range of flow conditions. Since the sensor is isolated from the wetted parts, it has long service life. Absence of any moving parts minimizes the maintenance requirements, of the instruments. However, the flowmeter should be used under the specified conditions of flow, pressure, temperature and viscosity in order to maintain high accuracy.

Piezoelectric pressure transducers $c$ an be used to monitor short term dynamic pressure conditions. These instruments are highly suitable to measure dynamic pressures in reacators, compressors, turbines, combustion chambers, blasts, explosions, shock waves, pulsations, and turbulences where fast response is required at very high static pressure levels. These instruments can be operated at $115 \mathrm{AC}, 60 \mathrm{~Hz}$, or at $24 \mathrm{VDC}$. The output of these instruments is 0-5 VDC, which can be used for remote mounted monitoring instruments. These transducers are available with different scale ranges, up to a maximum of $30,000 \mathrm{psi}$, and they can be used in a temperature range of $-100^{\circ} \mathrm{F}$ to $650^{\circ} \mathrm{F}$. Usage at higher temperatures above $650^{\circ} \mathrm{F}$ requires either a circulating cooling medium to the instrument or moving the amplifier to a remote location. 
5. LITERATURE SEARCH

The following papers were found through a search in DOE-RECON data base:

a. Recent Developments in Instrumentation and Measurement Techniques-by J. Paulou presented at Hydrotechnical Society of France seminar on strategy on measurement in water and air, Lyons, France, September 1981 .

b. Dry Solids Flowmeter--J. V. Walsh and C. K. Shen-Tu, C. F. Braun and Co., Alhambra, CA April 1978.

\section{MANUFACTURERS SURVEY}

The following listed manufacturers provide piezoelectric instruments:

a. Piezoelectric Flowmeters

Eastech, Inc., Atlantic Highlands, NJ

Accurate Metering Systems, Inc., Elk Grove, IL

b. Piezoelectric Pressure Transducers

Kistler Instrument Corp., Amherst, NY

Piezoelectric Products, Metuchen, $\mathrm{NJ}$

Vibro-Meter Corp., Billerica, MA

Seimens-Allis, Atlanta, GA 
1. IITLE - Radiation Type Instrument

2. APPLICATION - Level Measurement

3. THEORY OF OPERATION

Some of the high molecular weight materials tend to disintegrate creating three basic forms of radiation in this process, alpha, beta and gamma radiation. The type with the highest penetrating capability is gamma, which are short wave-length, high energy $X$-rays having no substance, only energy. The ability to penetrate various substances can be used as a measure of level in a tank. By positioning a gamma radiation source at the bottom of a tank, and a radiation detector at the top, and knowing the composition of the material in the tank, a detector scale can be calibrated in tank level units. Radioactive sources have various half-lives from minutes to thousands of years, as such it is appropriate to choose a source with a relatively long half-life in order to minimize frequent recalibrations. Appropriate shielding must be employed to avoid radiation exposure to plant personnel.

4. PLANT APPLICATIONS

Because the device is external to the process vessel, the usual problem sources such as high process pressures, temperatures, corrosive, viscous, adherent or abrasive fluid characteristics have no influence on its performance.

5. LITERATURE SEARCH

At this time a literature search is in progress, but no significant relevant material is available. 
6. MANUFACTURERS SURVEY

The following listed manufacturers provide radiation type level instruments:

Accuracy Corp., Columbus, $\mathrm{OH}$

Bestobell Mobrey, Controls \& Instumentation, Slough, Berkshire, England, U.K.

Electromatic Components, Ltd., Sub of Electromatic Intl., Streamwood, IL Endress \& Hauser, Inc., Greenwood, IN

ITT Corp., Barton Instruments, City of Industry, CA

Kay-Ray, Inc., Arlington Heights, IL

LeCroy Research Systems Corp., Spring valley, NY

Ludlum Measurements, Inc., Sweewater, TX

Moms \& Sons, Chicago, IL

Ramsey Italia, s.r.l., Milano, Italy

Relay Specialties, Inc., Fair Lawn, NJ

Ronan Engineering Co., Woodland Hills, CA

Ronan Engineering Co., Measurements Div., Florence, KY

Texas Nuclear Corp., a Div. of Ramsey Engineering, Austin, TX 
1. TITLE - Capacitance Variation

2. APPLICATION - Level Measurement

3. THEORY OF OPERATION

Capacitance probe installations are characterized by changes in vessel level causing a change in capacitance. The capacitance is measured by a bridge circuit excited by a high frequency oscillation. The probe is one plate of the capacitor, and the storage vessel wall, the other. The tankage acts as the dielectric. As level rises, vapors withlow dielectric constant are replaced by the higher dielectric of the stored material. The capacitance increases linearly with level. Capacitance changes are detected by an instrument calibrated in units of level.

\section{PLANT APPLICATIONS}

Typical applications are for below grade tanks where conventional differential pressure cells cannot be located, such as fuel oil storage tanks. Other applications include viscous, slurry and solids level measurements. Gas tank levels cannot be measured using this technique.

\section{LITERATURE SEARCH}

At this time a literature search is in progress, but no significant relevant material is available.

6. MANUFACTURERS SURVEY

a. The following listed manufacturers provide capacitance type level sensors:

Accuracy Corp., Columbus, $\mathrm{OH}$ Adar Corp., Houston, TX Balluff, Inc., Florence, $K Y$ Bernard Inc., Kennett Square, PA 
Combustion Engineering Invalco Measurement \& Control, Tulsa, OK Conax Buffalo Corp., Buffalo, NY

Controlatron, Hauppauge, NY

Delavan Corp., Di of Colt Industries, Scottsdale, AZ

Delta Controls Corp., Shreveport, LA

Drexelbrook Engineering Co., Horsham, PA

Electromatic Componensts, Ltd., Sub of Electromatic Intl., Streamwood, IL

Endress \& Hauser, Inc., Greenwood, IN

GPE Control, Brunswick Valve and Control Div., Morton Grove, IL Gaston County Dyeing Machine Co., Stanley, NC

Gordon Products, Inc., Brookfield, CT

Hammor Co., Inc., Chicago, IL

Mag-Con, Inc., St. Paul, MN

Magnetrol International, Inc., Downers Grove, IL

Omega Engineering, Inc., Stamford, CT

Omron Electronics; Inc., Schaumburg, IL

Princo Instruments, Inc., Southampton, PA

Rechner Electronics Industries, Inc., Niagra Falls, NY

Revere Corp. of America, Wallingford, CT

Riede systems, Inc., Minneapolis, MN

Robertshaw Controls Co., Anaheim, CA

Robertshaw Controls Co., Ind. Instrumentation Div., Broomall, PA

Sterling Technologies, Inc., Southfield, MI

Standberg Eng., Labs., Inc., Industrial Electronics Div.,

Greensboro, NC

Turch Multiprox, Inc., Minneapolis, MN

Visolux, Inc., Arlington Heights, IL

Warren-Knight Instrument Co., Philadelphia, PA

Zi-Tech Instrument Corp., Palo Alto, CA 
PROFESSIONAL SOCIETY COMMITTEES RELATED TO SENSORS

SPIE

IEEE 802.4
Committee Chairman

Thermal Infrared Sensing

for Diagnostics and Control

Working Group Chairman

Subcommittee Chairman

ISA/Internationa
Purdue Workshop

Digital Data

IEC Standard:

Technical

Committee 65

IEEE

Reactor Control

Instrumentation

ASME/Measurement Working Group Chairman Uncertainty

(PTC-19.1) and

Thermowells

(PTC-19.3.1)

ASME/Pressure

Measurement

(PTC-19.2)

ASME/F low

Measurement

Working Group Chairman

Working Group Chairman

(PTC - 19.5)
Herbert Kaplan

Honey Hill Tech. Co.

(203) 838-8600

Donald Loughry

Hewlett Packard

(408) 257-7000

Ext. 2454

Robert S. Crowder, Jr.

Engineering Dept.

Dupont Exp. Station 357

Wilmington, DE 19898

(302) 774-1664 (Bus.)

(302) 731-4860 (Home)

Les Oakes

ORNL

(615) 574-5527

Robert P. Benedict

(215) 565-1074
Joseph A. Sitvaggio

(609) 890-5660

David R. Keyser

(215) 441-1570 
ASME/Quality of Working Group Chairman

Steam (PTC-19.11)

ASME/Digital

Systems

Techniques

(PTC-19-.22)

ISA/Measurement Committee Chairman

Transducers (SP 37)

Working Group Chairman
ISA/Piezoelectric Committee Chairman

Pressure

Transducers

(SP37.10)
Ear1 E. Coulter

(904) 767-9697

Gary A. Julian

(303) 755-6783
Dan R. Hayes

Westinghouse Elec. Corp.

$\checkmark$ andenberg ABF

CA 93473

(805) 866-9969

Rolf C. Strahm

EG\&G Idaho Inc.

ARA-3

P.0.Box 1625

Idaho Falls, ID 83415

(208) 526-8256

Ivan Sturman

Bechtel Power Corp.

P. 0. Box 3965

MS 221/9/A-10

San Francisco, CA 94119

(4150 768-0913

David Braudaway

Sandia National Lab.

Sandia Base Div. 7241

Albuquerque, NM 87185

(505) 844-6556 
ISA/Genera1

Committee Chairman

Purpose Elec-

trical and

Electronic

Instrumentation

(SP82.1)

ISA/Turbine Flow Committee Chairman

Meter (SP 31)
Frank J. McGowan

The Boxboro Co. 38 Neponset Ave.

Foxboro, MA 02035
M. J. Ford

Pratt \& Whitney

Aircraft Co.

P. 0. Box 2691

West Palm Beach, FL 33402

(305) 840-5984

Art williams

Tex-A-Mation

P. 0. Box 135

La Porte, TX 77517

Stephen J. Kotzbert

NASA Langley

Research Center

Lawrence J. Reeves

Ford Aerospace

Communication Corp.

\section{IEEE Power}

Engineering

Society/Power

System Instru-

mentation and

Measurement
Subcommittee Chairman

Command Control

Communication and

Intelligence

Standards Coordinator

Richard Reid Hypotronics Inc.

P. 0. Drawer A

Brewster, NY 10509

(914) 279-8091 
Subcommittee Chairman

Digital Techniques in

Electrical Measurements

Subcommittee Chairman

Fiber Optics

Engineering

Society/Power

Systems Communi -

cation

IEEE Power

Engineering

Society/Power

Generation

IEEE Power

Engineering

Society/Power

Generation

IEEE Sonics and

UTtrasonics
Working Group Chairman

Power Plant Control and

Data Interfaces

Subcommittee Chairman

Power Plant Control and

Automation

Working Group Chairman

Distributed Digital Control

for Power Plants

Chairman

(617) 681-6025
Dr. John E. May

Bel 1 Labs

1600 Osgood Street

No. Andova, MA 01845

R. A. Malewski

Hydro Quebec Institute of Research

Varennes, Quebec Canada

JOL 2PO

D. C. Erickson

Bonneville Power

Admn - ENIC

P. 0. Box 3621

Portland, OR 97208

N. Pillai

Ontario Hydro

700 University Ave.

Toronto, ONT MSG1X6

Canada

P. M. Davidson

Philadelphia Elec. Co. 2301 Market St/58-1

Philadelphia, PA 19101

D. J. Damsker

531 Main Street R1010

New York, NY 10044

$y$
01845


IEEE Circuits Subcommittee Chairman and Systems
Digital Signal Processing

Subcommittee Chairman

a) Analog Signal Processing

b) Microprocessor Applications
J. A. Heinen

Prof. of Electrical

Engineering and Computer

Science Marquete Univ. $615 \mathrm{~N}, 11$ th Street

Mi iwaukee, WI 53233

(414) 224-3500

W. K. Jenkins

Prof. of Electrical

Engineering University of 111 . Urbana, IL 61801 (217) 333-6612

D. C. Cook Harris Corp. (305) 727-4363

G. R. Peacock Land Industries (215) 943-7882

David A. Braudaway Box 9 Sandia Park, NM 87047 (505) 844-6556

B. C. Johnson

Eneron

P. 0. Box 1330 2391 h, 35 South San Marcos, TX 78666

(512) 396-5880 